\title{
An isogenic panel of single App knock-in mouse models of Alzheimer's disease confers differential profiles of $\beta$-secretase inhibition and endosomal abnormalities
}

Naoto Watamura ${ }^{1,+}$, Kaori Sato ${ }^{1,2,+}$, Gen Shiihashi ${ }^{1,3}$, Ayami Iwasaki ${ }^{1,4}$, Naoko Kamano ${ }^{1}$, Mika

Takahashi $^{1}$, Misaki Sekiguchi ${ }^{1}$, Naomi Yamazaki ${ }^{1}$, Ryo Fujioka ${ }^{1}$, Kenichi Nagata ${ }^{5}$, Shoko Hashimoto $^{1}$, Takashi Saito ${ }^{1,6}$, Toshio Ohshima ${ }^{2}$, Takaomi C. Saido ${ }^{1 *}$ and Hiroki Sasaguri ${ }^{{ }^{*}}$

${ }^{1}$ Laboratory for Proteolytic Neuroscience, RIKEN Center for Brain Science, 2-1 Hirosawa, Wako, Saitama 351-0198, Japan

${ }^{2}$ Laboratory for Molecular Brain Science, Department of Life Science and Medical Bioscience, Waseda University, Shinjuku, Tokyo 162-8480, Japan

${ }^{3}$ Neurological Institute, Shonan Keiiku Hospital, 4360 Endo, Fujisawa, Kanagawa, 252-0816, Japan

${ }^{4}$ Yamaguchi University School of Medicine, 1-1-1 Minamikogushi, Ube, Yamaguchi, 755-8505, Japan

${ }^{5}$ Department of Functional Anatomy and Neuroscience, Nagoya University Graduate School of Medicine, Nagoya, Aichi 466-8550, Japan

${ }^{6}$ Department of Neurocognitive Science, Institute of Brain Science, Nagoya City University Graduate School of Medical Sciences, Nagoya, Aichi 467-8601, Japan

${ }^{+}$These authors contributed equally to this work.

*Corresponding authors: takaomi.saido@riken.jp; hiroki.sasaguri@riken.jp

TEL: +81-48-467-9715 


\section{SUMMARY}

We previously developed single App knock-in mouse models of Alzheimer's disease (AD) that harbor the Swedish and Beyreuther/Iberian mutations with or without the Arctic mutation $\left(A p p^{N L-}\right.$ G-F and $A p p^{N L-F}$ mice). These models showed the development of amyloid $\beta$ peptide (A $\beta$ ) pathology, neuroinflammation and cognitive impairment with aging. We have now generated App knock-in mice devoid of the Swedish mutations $\left(A p p^{G-F}\right.$ mice) and some additional mutants to address the following two questions: [1] Do the Swedish mutations influence the mode of $\beta$ secretase inhibitor action in vivo? [2] Does the quantity of C-terminal fragment of amyloid precursor protein (APP) generated by $\beta$-secretase $(\mathrm{CTF}-\beta)$ affect endosomal properties as previously reported as well as other pathological events? A $\beta$ pathology was exhibited by $A_{p p}^{G-F}$ mice from 6 to 8 months of age, and was accompanied by microglial and astrocyte activation. We found that a $\beta$-secretase inhibitor, verubecestat, inhibited $\mathrm{A} \beta$ production in $A p p^{G-F}$ mice, but not in $A p p^{N L-G-F}$ mice, indicating that the $A p p^{G-F}$ mice are more suitable for preclinical studies of $\beta$ secretase inhibition given that most AD patients do not carry Swedish mutations. We also found that the quantity of CTF- $\beta$ generated by various App knock-in mutants failed to correlate with endosomal alterations or enlargement, implying that CTF- $\beta$, endosomal abnormalities, or both are unlikely to play a major role in $\mathrm{AD}$ pathogenesis. This is the first $\mathrm{AD}$ mouse model ever described that recapitulates amyloid pathology in the brain without the presence of Swedish mutations and without relying on the overexpression paradigm. Thus, experimental comparisons between different App knock-in mouse lines will potentially provide new insights into our understanding of the etiology of AD. 


\section{INTRODUCTION}

Alzheimer's disease (AD), the most prevalent cause of dementia, has been intensively investigated worldwide for over 100 years since it was first reported ${ }^{1}$. There are currently, however, no efficacious disease-modifying treatments available for $\mathrm{AD}$, although aducanumab ${ }^{2}$, an anti-A $\beta$ human monoclonal antibody, was approved for use by the U.S. Food and Drug Administration in June 2021 following positive Phase 4 trial outcomes. To date, significant research advances have been achieved thanks to mouse models that recapitulate aspects of the AD pathophysiology seen in humans. Most AD mouse models overexpress mutant amyloid precursor protein (APP) or APP/presenilin 1 (PS1) cDNAs inserted into unknown loci of the host animals, which causes artificial aspects of their complex phenotypes ${ }^{3}$. We previously developed $A p p^{N L-F}$ and $A p p^{N L-G-F}$ knock-in mice that harbor the Swedish (KM670/671NL) and Beyreuther/Iberian (I716F) mutations - with or without the Arctic (E693G) mutation - that do not depend on APP or APP/PS1 overexpression for their pathophysiological phenotype. These App knock-in mice exhibit age-dependent neuritic plaques composed of amyloid $\beta$ peptide (A $\beta$ ) in the brain, followed by gliosis and memory impairment ${ }^{4}$.

It should be noted, however, that the Swedish mutations, located adjacent to the cleavage site of APP by $\beta$-secretase, results in a drastic increase in CTF- $\beta$ levels and influences the in vitro APP processing efficacy of $\beta$-secretase inhibitors ${ }^{5}$. The presence of Swedish mutations therefore renders the $A p p^{N L-F}$ and $A p p^{N L-G-F}$ lines as unsuitable for preclinical studies of $\beta$-secretase inhibitors. In effect, Swedish mutations are present in most APP transgenic mouse models that overexpress APP, and moreover, there is no single App knock-in mouse model that recapitulates amyloid pathology in the brain in the absence of Swedish mutations. In addition, recent cell-based studies have reported that CTF- $\beta$, not $\mathrm{A} \beta$, contributes to early endosomal dysfunction ${ }^{6}$. Although multiple lines of evidence indicate that aberrant events in the endosomal trafficking system may appear as a common cytopathology regardless of whether the AD is early- or late-onset 8,9101112 , it is not well understood if CTF- $\beta$ affects early endosomal dysfunction in vivo.

In this study, we used a CRISPR/Cas9 system to develop $A p p^{G-F / G-F}$ knock-in $\left(A p p^{G-F}\right)$ mice harboring the Arctic and Beyreuther/Iberian mutations but devoid of the Swedish mutations 13,14. Similar to the $A p p^{N L-F}$ and $A p p^{N L-G-F}$ lines, the $A p p^{G-F}$ line showed an age-dependent amyloid pathology, neuroinflammation and synaptic alteration. Acute administration of verubecestat ${ }^{15,16}$, a potent selective BACE1 inhibitor, reduced A $\beta$ levels in $A_{p p}^{G-F}$ mice, but not in $A_{p p}^{N L-G-F}$ mice. We also found that early endosomal enlargement was present in the brains of $A_{p p}^{G-F}$ mice even 
though the CTF- $\beta$ quantity was quantitatively comparable to that of WT mice. Our findings demonstrate that BACE1 activity can be appropriately evaluated in $A p p^{G-F}$ mice without the interference of the Swedish mutations and that endosome enlargement does not correlate with CTF- $\beta$ levels in vivo. 


\section{RESULTS}

\section{Generation of $A_{p p}{ }^{G-F}$ and $A p p^{h u A \beta}$ Mice By CRISPR/Cas9}

We previously developed $A p p^{N L-G-F}$ mice by manipulation of the mouse $A p p$ gene using a knockin strategy ${ }^{4}$. Exon 16 of the App gene contains the Swedish mutations (KM670/671NL) while exon 17 contains the Arctic and Beyreuther/Iberian mutations (Figure 1A). Firstly, single-guide RNA (sgRNA)-App-Exon16 and single-stranded oligodeoxynucleotide (ssODN) containing the WT sequence to substitute the Swedish mutations (NL670/671KM) together with Staphylococcus aureus Cas9 (SaCas9) mRNA, where the proto-spacer adjacent motif (PAM) sequence is required as NNGRRT, were injected into the cytoplasm of heterozygous zygotes of $A p p^{N L-G-F}$ mice. The PAM sequence overlapped with the Swedish mutations so that, when knock-in of the WT sequence occurred, it could prevent sequential cleavages by SaCas9 because the original PAM site had disappeared (Figures 1A and 1B). Sanger sequencing analysis revealed that the desired substitution via homology-directed repair occurred successfully in the App ${ }^{N L-G-F}$ allele of the founder mice with an efficiency of 10.8\% (Figure 1C). Crossing the founder mice with WT mice to generate F1 mice, we confirmed that the Swedish mutations were fully removed from the $A p p^{N L-G-F}$ allele (Figure 1C). Using an identical strategy in $A p p^{N L}$ zygotes (see methods), we also generated $A p p^{h u A \beta}$ mice that carry only the humanized $\mathrm{A} \beta$ sequence in without any familial $\mathrm{AD}$ causing mutation. We confirmed that there were no unexpected mutations in exons 16, 17 and 18 of the $A p p$ gene in $A p p^{G-F}, A p p^{h u A \beta}$ mice and others (Figure S1), indicating that all these lines are isogenic. $A p p^{G-F / w t}$ mice were then intercrossed to obtain homozygous $A p p^{G-F / G-F}$ mice that were viable. To explore the off-target effects of CRISPR/Cas9-mediated genome editing in the founder mice, we searched for potential off-target sites using the online tool COSMID ${ }^{17}$ and CasOFFinder ${ }^{18}$ (Figure 1D). Targeted sequencing analysis focusing on the candidate genomic regions revealed that no off-target modification took place in the founder mice of $\operatorname{App}^{G-F}$ and App ${ }^{\text {huA }}$ mice.

\section{Neuropathology of $A p p^{G-F}$ Mice}

We next analyzed the extent of amyloid pathology in the $A p p^{G-F}$ mice. $\mathrm{A} \beta_{42}$ levels in the cortex were age-dependently increased in the Tris- $\mathrm{HCl}$ and Guanidine- $\mathrm{HCl}(\mathrm{GuHCl})$ soluble fractions, with $A \beta_{40}$ levels remaining relatively stable (Figures $\mathbf{2 A}$ and $\mathbf{2 B}$ ). We also observed that progressive amyloid pathology mainly in the cortex and hippocampus occurred in an agedependent manner (Figures 2C and 2D). Initial deposition of $A \beta$ was observed around 4 months 
of age in the $A p p^{G-F}$ mice. At 12 months, $\mathrm{A} \beta$ deposition in the brains of $A p p^{G-F}$ mice detected in a much larger area than that in the $A p p^{N L-F}$ mice, but at a lower level to that in $A p p^{N L-G-F}$ mice (Figure S2). In addition, we analyzed the $A \beta$ species constituting amyloid plaques in the $A p p^{G-F}$ mice using N-, C-terminal $\left(A \beta_{40}, A \beta_{42}\right)$ and $A \beta_{3(\mathrm{pE})-\mathrm{X}}\left(\mathrm{pE}\right.$ : pyroglutamate) specific antibodies. $A \beta_{40}, A \beta_{42}$ and $A \beta_{3(\mathrm{pE})-\mathrm{X}}$ species were detected in the brain with a predominant deposition of $A \beta_{42}$ over $A \beta_{40}$ (Figure 2E). These results are consistent with the neuropathology observed in sporadic AD patients and in $A p p^{N L-F}$ and $A p p^{N L-G-F}$ mice ${ }^{4}$.

Chronic inflammation surrounding $A \beta$ plaques in the brain is a pathological hallmark of AD. We therefore investigated the status of glial cells surrounding amyloid plaques in the $\mathrm{App}^{G-}$ ${ }^{F}$ mice. Reactive astrocyte and activated microglia are pathological signs of neuroinflammation, with evidence of both being observed (Figure 2F). We also examined pre- and post-synaptic alterations in brain slices and detected loss of synaptophysin and PSD-95 immunoreactivity near the $\mathrm{A} \beta$ plaques, which is consistent with those in other App knock-in mice (Figure 2G) ${ }^{4}$.

\section{Assessment of BACE1 Inhibition in App $^{G-F}$ Mice}

The Swedish mutations have been considered to underlie the decreased APP processing potency of $\beta$-secretase inhibitors. Previous studies have shown that $\beta$-secretase inhibition is less efficacious in cells stably overexpressing the APP-containing Swedish mutations than from cells transfected with wild-type APP ${ }^{19,20}$. To compare the potency of $\beta$-secretase inhibition in animal models - with or without Swedish mutations in the APP gene - not relying on the overexpression paradigm, we administrated verubecestat, a potent BACE1 inhibitor, to 3-month-old WT, $A p p^{N L-}$ $G-F$ and $A p p^{G-F}$ mice following a previously reported experimental protocol ${ }^{16}$. We found that a single oral administration of verubecestat at the dose of $10 \mathrm{mg} / \mathrm{Kg}$ significantly reduced both $\mathrm{A} \beta_{40}$ and $\mathrm{A} \beta_{42}$ levels in the cortices of $A p p^{G-F}$ mice, but not in $A p p^{N L-G-F}$ mice, 3 hours after treatment (Figures 3A-3D). These results indicate that the Swedish mutations are responsible for the poor potency of BACE1 inhibitors in vivo and that $\mathrm{App}^{G-F}$ mice could serve as a powerful tool for the precise characterization of BACE1 and candidate inhibitory compounds.

\section{Relationship Between the Quantity of CTF- $\beta$ and Endosomal Abnormality in vivo}

Several studies have reported that the Swedish mutations alter the APP processing and shift the processing towards an amyloidogenic pathway via a competitive behavior between $\alpha$ - and $\beta$ secretases ${ }^{5,21}$. In an earlier study, we showed that the ratio of CTF- $\beta / \alpha$ levels in $A p p^{N L-F}$ and $A p p^{N L-}$ ${ }^{G-F}$ mice is higher than that in wild-type mice ${ }^{4}$. Here, we used five different $A p p$ knock-in lines 
and WT mice to examine the effect of the mutations on the quantity of CTF- $\beta$ and the extent of endosomal dysfunction (Table 1). The ratio of CTF- $\beta / \alpha$ in $A p p^{G-F}$ mice was much lower compared to $A p p^{N L}, A p p^{N L-F}$ and $A p p^{N L-G-F}$ mice with no alteration of APP levels (Figures $4 \mathrm{~A}$ and S3A-S3E). This finding indicates a slight shift to the $\beta$-cleavage pathway. We next examined whether CTF- $\beta$ affects endosomal function in vivo. Some groups suggest that accumulated CTF$\beta$ itself induces endosome abnormalities independent of $A \beta$ toxicity ${ }^{6,7}$. The quantity of CTF- $\beta$ in the brains of $A_{p p}{ }^{G-F}$ mice was comparable to that of WT controls (Figures 4A and 4B). We focused on early endosomal antigen 1 (EEA1) as an early endosome marker and performed immunohistochemical analyses of the hippocampal CA1 region in six mouse lines: WT, App ${ }^{\text {huA }}$, $A p p^{N L}, A p p^{N L-F}, A p p^{G-F}$ and $A p p^{N L-G-F}$ knock-in mice. We detected a significant increase in the mean EEA1 ${ }^{+}$area in the CA1 pyramidal cell layer of five mutant lines compared with that of WT mice (Figures 4C and 4D). Kwart et al. demonstrated that endosome enlargement is a common pathology in familial APP mutant iPSC neurons, and that the quantity of CTF$\beta$ correlates with endosome abnormality. We consistently observed a significant alteration of the distribution of endosome size in the five mutant mouse lines, including $A p p^{\text {huA } \beta}$ knock-in mice, compared with that of wild-type mice (Figure 4E). This was seen as an increase in the ratio of larger endosomes $\left(>1 \mu \mathrm{m}^{2}\right)$ and a decrease in the ratio of smaller endosomes $\left(<0.5 \mu \mathrm{m}^{2}\right)$ (Figure 4E). However, CTF- $\beta$ levels did not correlate with endosome enlargement. Of note, endosomal sizes were enlarged in the brains of $A p p^{G-F}$ mice, the extent of which was similarly observed in $A p p^{N L-G-F}$ mice irrespective of large differences in CTF- $\beta$ levels (Figures $4 \mathbf{B}$ and $4 F$ ). We sequenced the C-terminal region of APP in our App knock-in mouse lines and excluded the possibility that unexpected mutation was causing this alteration (Figure S1). These findings suggest that early endosomal enlargement might be caused by not only CTF- $\beta$ but also by other toxic agents including human $A \beta$ secretion in mouse brains.

\section{DISCUSSION}

In the present study, by removing the Swedish mutation from $A p p^{N L-G-F}$ mice we developed a new App knock-in line, $A p p^{G-F}$, which harbors both the Arctic and Beyreuther/Iberian mutations. The $A p p^{G-F}$ mice exhibited an age-dependent and typical amyloid pathology, neuroinflammation, characterized by reactive astrocytes and activated microglia surrounding the $A \beta$ plaques, and aberrant pre- and post-synaptic structures near the plaques. Verubecestat intervention effectively 
reduced $\mathrm{A} \beta$ levels in the cortices of $A p p^{G-F}$ mice, but not in the conventional App knock-in mice containing the Swedish mutation. Endosomal enlargement was also observed, although the CTF$\beta$ levels in the brains of $A p p^{G-F}$ mice was comparable to those of WT mice.

$\mathrm{A} \beta$ deposition in the brains of $A p p^{G-F}$ mice occurs from around 4 months of age, compared to around 2 months of age in $A p p^{N L-G-F}$ mice and 6 months in $A p p^{N L-F}$ mice ${ }^{4}$, suggesting that the $A p p^{G-F}$ mice serve as "a moderate model" of the three lines from the point of view of amyloidosis in the mouse brain (Figure S2). $A p p^{G-F}$ mice also showed an age-dependent amyloid pathology in the subcortical area as well as in the cortex and hippocampus, which is consistent with human carriers of the Arctic mutation ${ }^{22}$. This is the first AD mouse model that recapitulates amyloid pathology in the brain, but does not harbor the Swedish mutation and is not dependent on APP overexpression.

Previous studies based on transgenic mice overexpressing the $A P P$ gene with familial mutations and CRISPR/Cas9-mediated genomic modified iPSCs indicated that AD-associated early endosomal enlargement depends on the excess accumulation of CTF- $\beta$, but not A $\beta^{6,7,23-27}$. On the other hand, other studies have reported that $A \beta$ toxicity is indeed a causative factor for impaired endocytic sorting ${ }^{28-30}$. In this study, using App knock-in mice, we observed early endosomal abnormalities in hippocampal CA1 pyramidal neurons both with or without CTF$\beta$ overproduction compared to WT mice (Figures 4 and S4). Given that $A \beta_{42}$ levels reached a plateau and that $\mathrm{A} \beta$ plaque formation was spread abundantly in the hippocampi of $A p p^{G-F}$ mice as young as 12 months of age (Figures $\mathbf{2 A}$ and $\mathbf{2 B}$ ), A $\beta$ species themselves, independent of CTF$\beta$ accumulation, are also likely to cause early endosomal enlargement in vivo. Future analyses on concerning which $A \beta$ peptide(s) such as $A \beta_{40}, A \beta_{42}, A \beta_{3(\mathrm{pE})-x}$ are responsible for altering the endocytic system are required to elucidate the underlying mechanism(s). Our results show that humanization of $A \beta$ alone induces endosomal enlargement in mice, which is consistent with a transcriptomic study using weighed gene co-expression network analysis (WGCNA) indicating that Eeal is one of the highly correlated genes explaining biological alterations in the hippocampi of huA $\beta-\mathrm{KI}$ mice ${ }^{31}$. On the other hand, recent studies indicate that endosomal enlargement occurs via an APP-independent pathway ${ }^{32}{ }^{33}$. Taken together, endosomal trafficking defects associated with $\mathrm{AD}$ cytopathogenesis may be occur via different means such as CTF- $\beta$-dependent, A $\beta$ dependent and APP-independent pathways.

A large number of BACE1 inhibitors have been explored and investigated as potent disease-modifying drugs in the $\mathrm{AD}$ research field, but all of them, to our knowledge, have failed to show efficacy in clinical trials. However, as the A673T (Icelandic) mutation ${ }^{34}$ positively 
established the proof-of-concept that the inhibition of $\beta$-secretase cleavage reduces the risk of AD onset, the discovery of BACE1 inhibitory compounds that pass through the blood-brain barrier and directly abrogate $A \beta$ production in human brains remains a promising path to treat $A D$ patients. Although single $A p p^{N L-F}$ and $A p p^{N L-G-F}$ knock-in mice have been used in more than 500 laboratories and pharmaceutical companies worldwide as second-generation mouse models of $\mathrm{AD}^{4}$, these mice are not compatible with BACE1-related studies due to the presence of Swedish mutations. Our results provide consistent evidence that the Swedish mutations hinder the BACE1 inhibitory activities of verubecestat in vivo, similar to several reports showing the reduced activity of BACE1 inhibitors including not just verubecestat ${ }^{19}$ but also other drug candidates in mice harboring the Swedish mutations ${ }^{35}{ }^{21}$. Thus, $A p p^{G-F}$ mice now profile as a novel type of single App-KI mice without the interference of the Swedish mutations. The potential exists for these mice to be used to efficiently and precisely to identify active compounds for BACE1 inhibition in vivo that might have been overlooked in a vast number of studies in which $\mathrm{AD}$ model mice were used that contained the Swedish mutations and were based on an APP overexpression paradigm. Our range of single $A p p$ knock-in mice including the $A p p^{N L-F}, A p p^{N L-G-F}$ and $A p p^{G-F}$ lines, are available for use by research groups and companies worldwide who can choose the AD mouse model line most suited to the purpose of their study.

\section{EXPERIMENTAL MODEL DETAIL}

\section{Mice}

All animal experiments were conducted in compliance with regulations stipulated by the RIKEN Center for Brain Science. $A p p^{N L-F}$ or $A p p^{N L-G-F}$ mice expressing two or three familial AD mutations [Swedish (KM670/671NL) and Beyreuther/Iberian (I716F) with or without the Arctic (E693G) mutation] driven by the endogenous promoter, as well as the humanized $\mathrm{A} \beta$ sequence, were generated described previously ${ }^{4} . A p p^{N L-G-F}$ and ICR mice were used as zygote donors and foster mothers. C57BL/6J and $A p p^{N L}$ mice were prepared as controls ${ }^{4}$. All mutant mice used in this study were homozygous for the expressed mutations. Both male and female mice were used in our experiments. All mice were bred and maintained in accordance with regulations for animal experiments promulgated by the RIKEN Center for Brain Science.

\section{METHODS DETAILS}




\section{Generation of $A p p^{G-F}$ mice}

sgRNA targeting mouse App exon 16 was designed in silico utilizing the CRISPR design tool ${ }^{36}$. To reduce the possibility of off-target events, SaCas9 that recognizes NNGRRT as the PAM site was selected to introduce double-stranded breaks. ssODN was designed to cause NL670/671KM substitution (AATCTA>AAGATG) overlapping the PAM region so that the oligonucleotide did not include silent mutations, thus preventing re-binding and re-cutting after the desired genome modification via homology -directed repair. A plasmid vector (Addgene, \#61591) was used for in vitro transcription of SaCas9 mRNA, and sgRNA was synthesized as described previously ${ }^{37}$. Information on the primers and oligonucleotides used for the in vitro synthesis of CRISPR tools is listed in Table S1. The prepared SaCas9 mRNA (100 ng/ $\mu \mathrm{l})$ and $\operatorname{sgRNA}(100 \mathrm{ng} / \mu \mathrm{l})$ along with ssODN $(100 \mathrm{ng} / \mu \mathrm{l})$ were co-injected into the cytoplasm of $A p p^{N L-G-F / w t}$ zygotes. Founder mice were identified by PCR and sequencing analysis of the targeted site and crossed with wild-type mice to obtain heterozygous F1 mice.

\section{Generation of $A p p^{h u A \beta}$ mice}

To generate $A p p^{\text {huA } \beta}$ mice that carried only the humanized A $\beta$ sequence, virtually the same strategy was used to that employed for developing $A p p^{G-F}$ mice. The prepared sgRNA, mRNA and ssODN were identical to those used for $A p p^{G-F}$ mice, with the only different being that $A p p^{N L}$ zygotes instead of $A p p^{N L-G-F}$ zygotes were used for injecting genome editing tools. Potential offtarget sites were also identical as those for $A p p^{G-F}$ mice.

\section{Off-target effects analysis}

Candidate sequences were identified in silico using COSMID (https://crispr.bme.gatech.edu/) ${ }^{17}$ and Cas-OFFinder (http://www.rgenome.net/cas-offinder/) ${ }^{18}$ allowing up to $3 \mathrm{bp}$ mismatches and $1 \mathrm{bp}$ DNA and/or RNA bulge. Genomic DNA extracted from mouse tails was amplified by PCR with the primers listed in Table S2. All genomic sequences of the amplicons were analyzed by Sanger sequencing using a DNA sequencer (ABI 3730x1).

\section{Genotyping}

Genomic DNA was extracted from mouse tails in lysis buffer $(10 \mathrm{mM} \mathrm{pH} 8.5$ Tris-HCl, $5 \mathrm{mM}$ pH 8.0 EDTA, $0.2 \%$ SDS, $200 \mathrm{mM} \mathrm{NaCl}, 20 \mu \mathrm{g} / \mathrm{ml}$ proteinase $\mathrm{K}$ ) through a process of ethanol precipitation. Purified DNA was subjected to PCR and followed by Sanger sequencing analysis 
with the specific primers according to a previous report employing $A p p-K I$ mice, including $A p p^{N L}$, $A p p^{N L-F}$ and $A p p^{N L-G-F}$ strains $^{4}$. Genotyping primers for $A p p^{G-F}$ mice are listed in Table S2.

\section{Western blotting}

Mouse brain tissues were homogenized in lysis buffer containing $50 \mathrm{mM}$ Tris $\mathrm{pH}$ 7.6, $0.15 \mathrm{M}$ $\mathrm{NaCl}, 1 \%$ Triton and cOmplete protease inhibitor cocktail (Roche Diagnostics) using a Multibeads shocker (YasuiKikai). Homogenates were incubated at $4{ }^{\circ} \mathrm{C}$ for $1 \mathrm{~h}$ and centrifuged at 15000 rpm for 30 minutes, and the supernatants were collected as loading samples. Concentrations of protein samples were measured with the aid of a BCA protein assay kit (Thermo Fisher Scientific). Equal amounts of proteins were subjected to sodium dodecyl sulfate-polyacrylamide gel electrophoresis (SDS-PAGE) and transferred to PVDF membranes. For detection of APP-CTFs, delipidated samples were loaded onto membranes and boiled for $5 \mathrm{~min}$ in PBS before blocking with ECL primer blocking buffer (GE Healthcare). Membranes were incubated at $4{ }^{\circ} \mathrm{C}$ with primary antibodies against APP (MAB348, Millipore, 1:1000) or APP-CTFs (A8717, SigmaAldrich, 1:1000) with GAPDH (HRP-60004, Proteintech, 1:150000) as a loading control. Targeted proteins were visualized with ECL select (GE Healthcare) and a LAS-3000 Mini Lumino image analyzer (Fujifilm).

\section{Immunohistochemistry}

Paraffin-embedded mouse brains were sectioned (thickness $4 \mu \mathrm{m}$ ) and subjected to deparaffinization processing; antigen retrieval was then performed by autoclaving at $121{ }^{\circ} \mathrm{C}$ for 5 min. Brain sections were treated with $0.3 \% \mathrm{H}_{2} \mathrm{O}_{2}$ in methanol solution for 30 min to inactivate endogenous peoxidases. Sections were rinsed with TNT buffer $(0.1 \mathrm{M}$ Tris $\mathrm{pH} 7.5,0.15 \mathrm{M} \mathrm{NaCl}$, $0.05 \%$ Tween20), blocked using a TSA Biotin System kit and incubated at $4{ }^{\circ} \mathrm{C}$ overnight with primary antibodies diluted in TNB buffer $(0.1 \mathrm{M}$ Tris $\mathrm{pH} 7.5,0.15 \mathrm{M} \mathrm{NaCl})$. Primary antibody dilution ratios are listed in Table S3. Sections were washed, incubated with biotinylated secondary antibody and a tyramide signal amplification system used to detect amyloid pathology. For detection of neuroinflammatory signs and early endosome pathology, secondary antibodies conjugated with Alexa Fluor 555 diluted in TNB buffer or $0.2 \%$ casein in PBS were used. Sections were stained for 15 min with Hoechst33342 (Thermo Fisher Scientific) diluted in PBS, and then mounted with PermaFluor (Thermo Fisher Scientific). Section images were obtained using a confocal laser scanning microscope FV-1000 (Olympus) and a NanoZoomer Digital Pathology C9600 (Hamamatsu Photonics). Quantification of immunoreactive signals was performed using 
Metamorph Imaging Software (Molecular Devices) and Definiens Tissue Studio (Definiens).

\section{Enzyme-linked immunosorbent assay (ELISA)}

Mouse brain samples were homogenized in lysis buffer $(50 \mathrm{mM}$ Tris- $\mathrm{HCl}, \mathrm{pH} 7.6,150 \mathrm{mM} \mathrm{NaCl}$ and protease inhibitor cocktail) using a Multi-beads shocker (YasuiKikai). The homogenates were centrifuged at $70000 \mathrm{rpm}$ at $4^{\circ} \mathrm{C}$ for $20 \mathrm{~min}$, and the supernatant was collected as a Tris-Soluble (TS) fraction to which $1 / 11$ vol of $6 \mathrm{M}$ guanidine- $\mathrm{HCl}(\mathrm{GuHCl})$ in $50 \mathrm{mM}$ Tris and protease inhibitors were added. The pellet was loosened in lysis buffer with a Pellet Pestle (KIMBLE), dissolved in $6 \mathrm{M} \mathrm{GuHCl}$ buffer, and sonicated at $25^{\circ} \mathrm{C}$ for $1 \mathrm{~min}$. The sample was incubated for 1 hour at room temperature and then subjected to centrifugation at $70000 \mathrm{rpm}$ at $25^{\circ} \mathrm{C}$ for $20 \mathrm{~min}$. The supernatant was collected as a GuHCl-soluble fraction. Tris-soluble and GuHCl-soluble fractions were applied to 96-well plates using an A $\beta$ ELISA kit (Wako) according to the manufacturer's instructions. For detection of Arctic $\mathrm{A} \beta$ produced from the brains of $A p p^{N L-G-F}$ and $A p p^{G-F}$ mice, standard curves were drawn using human $\mathrm{A} \beta$ peptides carrying the Arctic mutation as described previously ${ }^{4}$.

\section{Verubecestat administration}

Verubecestat (ChemScene) dissolved in PBS was administrated orally to 3-month-old mice using a flexible sonde (FUCHIGAMI) at a single dose of $10 \mathrm{mg} / \mathrm{kg}$ according to Kennedy et a ${ }^{16}$. Three hours after a single treatment mouse brains were dissected and stored at $-80{ }^{\circ} \mathrm{C}$.

\section{QUANTIFICATION AND STATISTICAL ANALYSIS}

All data are shown as the mean \pm SEM within each figure. For comparisons between two groups, data were analyzed by Student's- or Welch's- $t$-test or Mann-Whitney test. For comparisons among more than three groups, we used one-way analysis of variance (ANOVA) followed by Dunnett's post hoc analysis or Tukey's post hoc analysis. All statistical analysis were performed using GraphPad Prizm 7 software (GraphPad software). Levels of statistical significance were presented as a $P$-values: $* P<0.05,{ }^{*} P<0.01, * * * P<0.001$.

\section{AUTHOR CONTRIBUTIONS}

NW, KS, KN, TS, TCS and HS designed the research plan. NW, KS, GS, AI, NK, MT, MS, NY, RF, NW, KI and ST performed the experiments. NW, KS, KN, TS, TCS and HS analyzed and interpreted data. HS, KS, NW, SH, TS and TCS wrote the manuscript together. HS, TO, 
TS and TCS supervised the entire research.

\section{ACKNOWLEDGEMENTS}

We thank Nobuhisa Iwata, Nagasaki University, for valuable discussions. We also thank Yukiko Nagai-Watanabe for secretarial work. This work was supported by AMED under Grant Number JP20dm0207001 (Brain Mapping by Integrated Neurotechnologies for Disease Studies (Brain/MINDS)) (TCS) and JSPS KAKENHI Grant Number JP18K07402 (HS).

\section{CONFLICTS OF INTEREST}

The authors declare no conflicts of interest. 
A

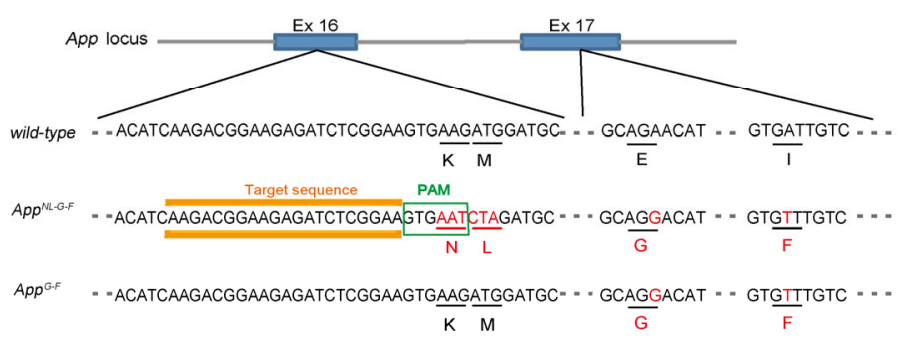

C

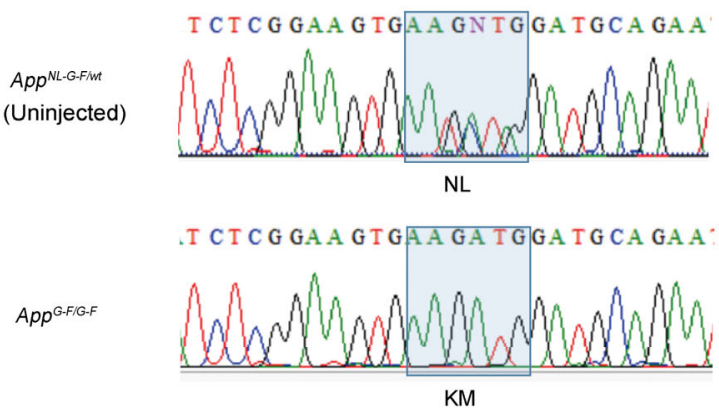

B

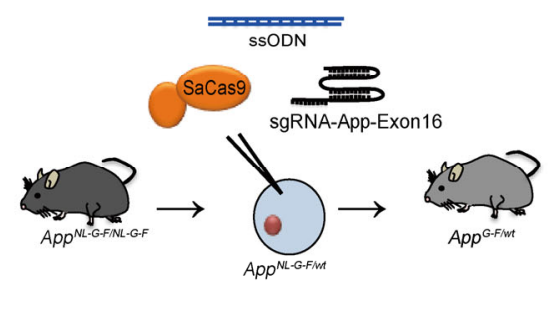

D

\begin{tabular}{lll} 
& Region & Gene symbol \\
\hline OFF1 & Chr2:161795409-161795435 & Intergenic \\
OFF2 & Chr17:80970728-80970755 & Tmem178 \\
OFF3 & Chr5:32069134-32069161 & Babam2 \\
OFF4 & Chr14:81773617-81773644 & Intergenic \\
OFF5 & Chr2:167197920-167197948 & Ptgis \\
OFF6 & Chr9:16725904-16725932 & Intergenic \\
OFF7 & Chr8:127927583-127927609 & Intergenic \\
OFF8 & Chr12:104727930-104727956 & Dicer1 \\
OFF9 & Chr5:126895554-126895580 & Intergenic \\
OFF10 & Chr13:32000264-32000290 & Gmds
\end{tabular}

\section{Figures}

\section{Figure 1. Generation of the single $A p p^{G-F}$ knock-in mice}

(A) Exact sequences showing sgRNA (orange) with the PAM site (green) in the mouse App gene. Red characters represent the Swedish (KM670/671NL), Arctic (E693G) and Beyreuther/Iberian (I716F) mutations, respectively. (B) Schematic illustration of CRISPR/Cas9-mediated genome editing in $A p p^{N L-G-F}$ knock-in mouse zygotes by microinjection. (C) Sanger sequencing results determined $A p p^{N L-G-F / w t}$ (upper panel) and $A p p^{G-F / G-F}$ genotype (lower panel). The desired mutation loci (NL670/671KM) are indicated as a rectangular shape in blue shading. See also Figure S1. (D) Regional information of potential off-target sites which were identified using Cas-OFFinder (http://www.rgenome.net/cas-offinder/) and COSMID (https://crispr.bme.gatech.edu/). 


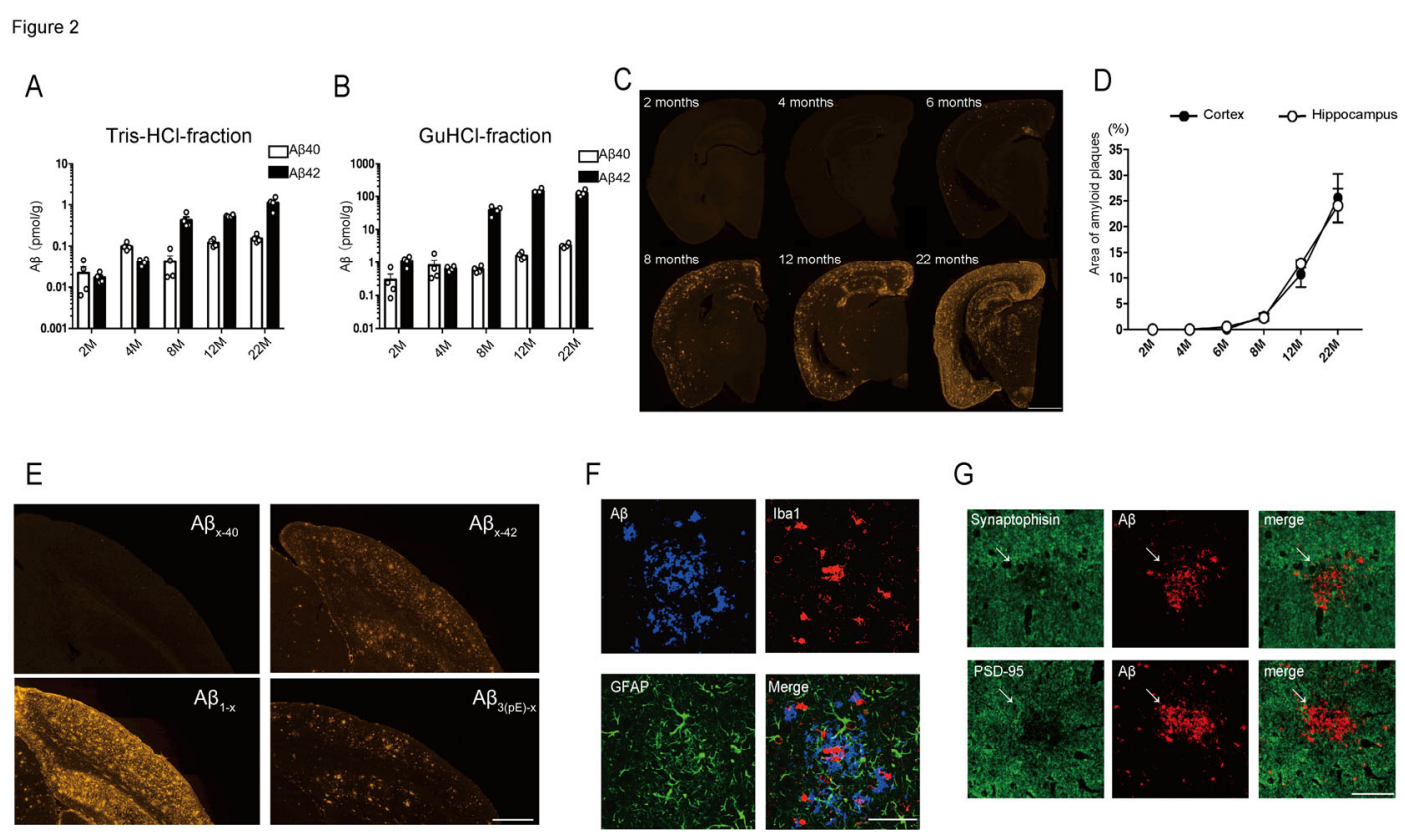

Figure 2. Neuropathology of $A p p^{G-F}$ mice

(A-B) $\mathrm{A} \beta$ content detected by ELISA using Tris- $\mathrm{HCl}$ soluble fraction (A) and $\mathrm{GuHCl}$ soluble fraction (B) of the cortices of $A p p^{G-F}$ mice at 2- 4-, 8-, 12- and 22 months (n=4 at each time point). Each bar represents the mean \pm SEM. (C) Immunohistochemistry images showing $A \beta$ deposition as indicated by immunostaining with N1D antibody against $A \beta_{1-5}$. Scale bars indicate $1 \mathrm{~mm}$. (D) Quantitative analysis of amyloid plaque areas in the cortices and hippocampi of $\mathrm{App}^{G-}$ ${ }^{F}$ mice at 2-, 4-, 8- and 12 months ( $\mathrm{n}=4$ at each time point) and at 22 months (n=3). Each bar represents the mean \pm SEM. (E) Specific antibodies against $N-\left(A \beta_{1-x}\right.$ and $\left.A \beta_{3(\mathrm{pE})-\mathrm{x}}\right)$ and $C$ $\left(A \beta_{x-40}\right.$ and $\left.A \beta_{x-42}\right)$ terminus of $A \beta$ reveal the deposition of each species of $A \beta$ in the brains of $22-$ month-old $A p p^{G-F}$ mice. Scale bars represent $500 \mu \mathrm{m}$. (F) Inflammatory responses in the cortices of $A p p^{G-F}$ mice at 22 months. Astrocytes (green) and microglia (red) can be seen surrounding $\mathrm{A} \beta$ (blue), as detected by triple staining with antibodies against GFAP, Iba1 and the N-terminus of human A $\beta$ (82E1), respectively. Scale bars represent $100 \mu \mathrm{m}$. (G) Synaptic alteration detected in the hippocampus of a 22-month-old $A p p^{G-F}$ mouse. A $\beta$ detected by $4 \mathrm{G} 8$ antibody against $\mathrm{A} \beta_{17-24}$ was double stained with synaptophysin antibody as a presynaptic marker or with PSD95 antibody as a postsynaptic marker. White arrows indicate synaptic loss near A $\beta$ aggregation. Scale bars represent $25 \mu \mathrm{m}$. 
Figure 3
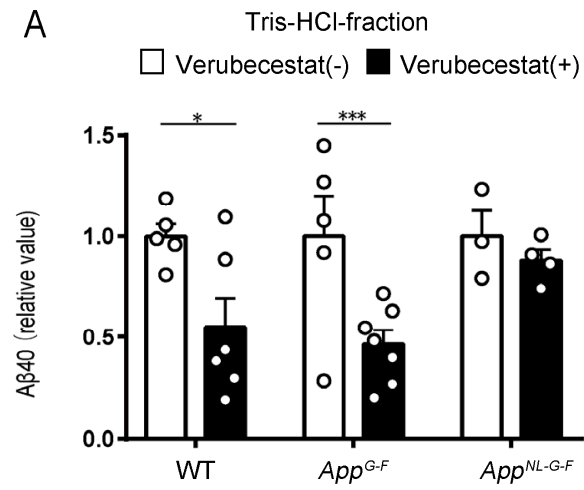

C

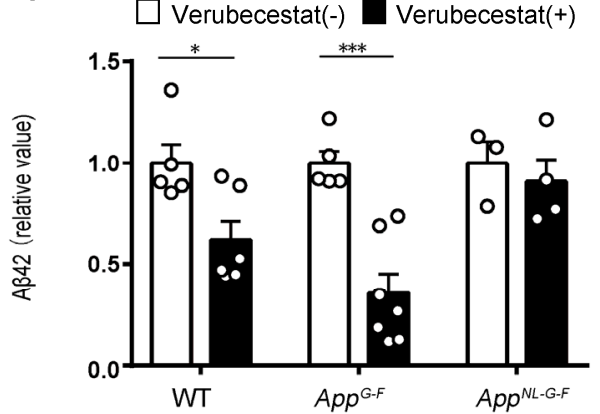

B

$\square$ Verubecestat(-) $\square$ Verubecestat(+)

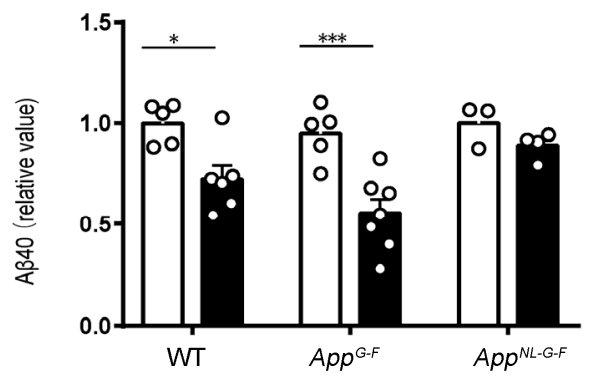

$\mathrm{D}$

GuHCl-fraction

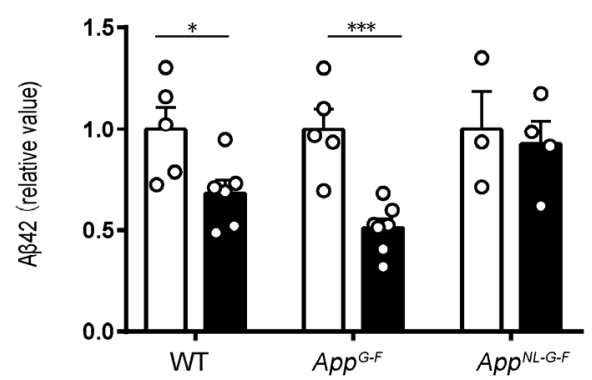

Figure 3. Removal of the Swedish mutations rescues the BACE1 inhibitory effect of verubecestat

(A-D) $\mathrm{A} \beta_{40}$ and $\mathrm{A} \beta_{42}$ levels detected by ELISA were decreased both in the Tris- $\mathrm{HCl}$ fraction (A, C) and $\mathrm{GuHCl}$ fraction $(\mathrm{B}, \mathrm{D})$ of 3-month-old wild-type and $A p p^{G-F}$ mice, but not in $\mathrm{App}^{N L-G-F}$ mice. Each bar represents the mean \pm SEM. $* P<0.05, * * P<0.01, * * * P<0.001$. (WT; verubecestat $(+) \mathrm{n}=5,(-) \mathrm{n}=6, A_{p p}^{G-F} ;(+) \mathrm{n}=5,(-) \mathrm{n}=7$ and $A p p^{N L-G-F} ;(+) \mathrm{n}=3,(-) \mathrm{n}=4$, Student's t-test). 
Figure 4

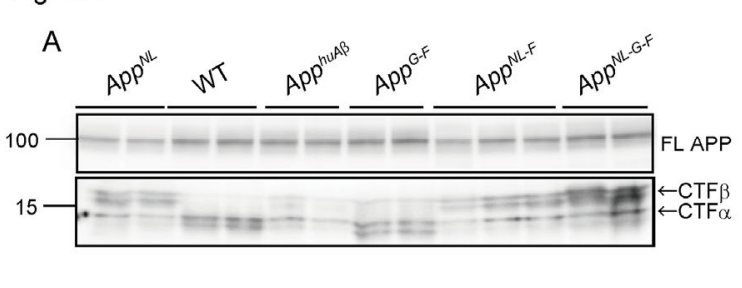

C
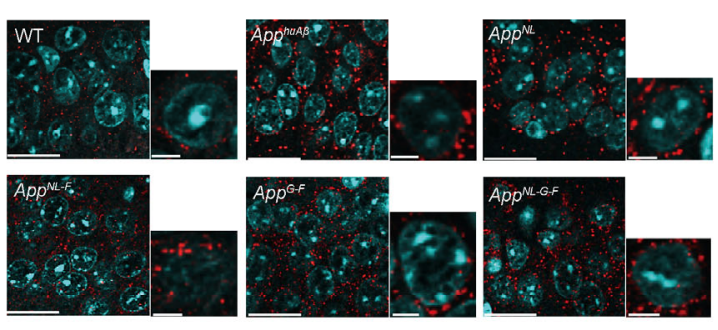

$\mathrm{E}$

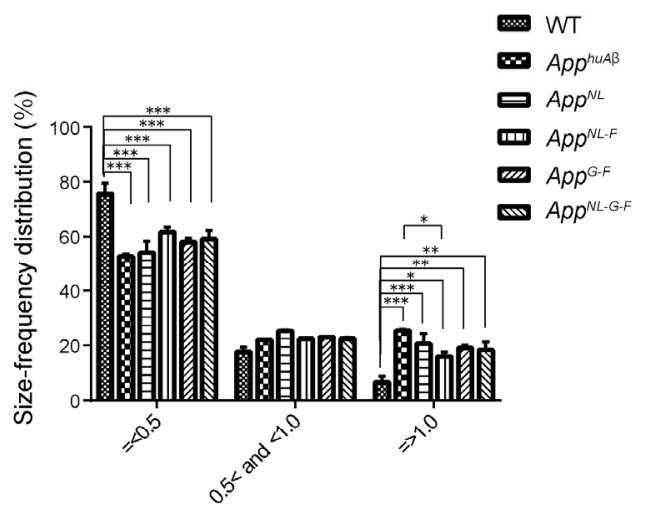

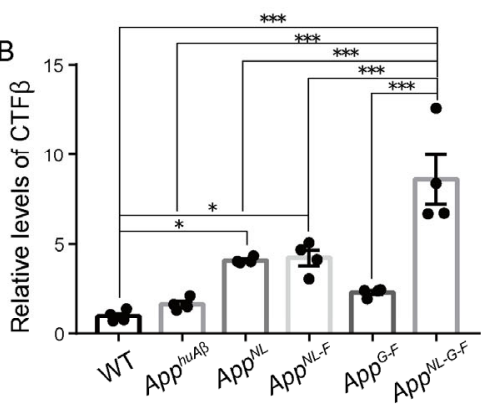
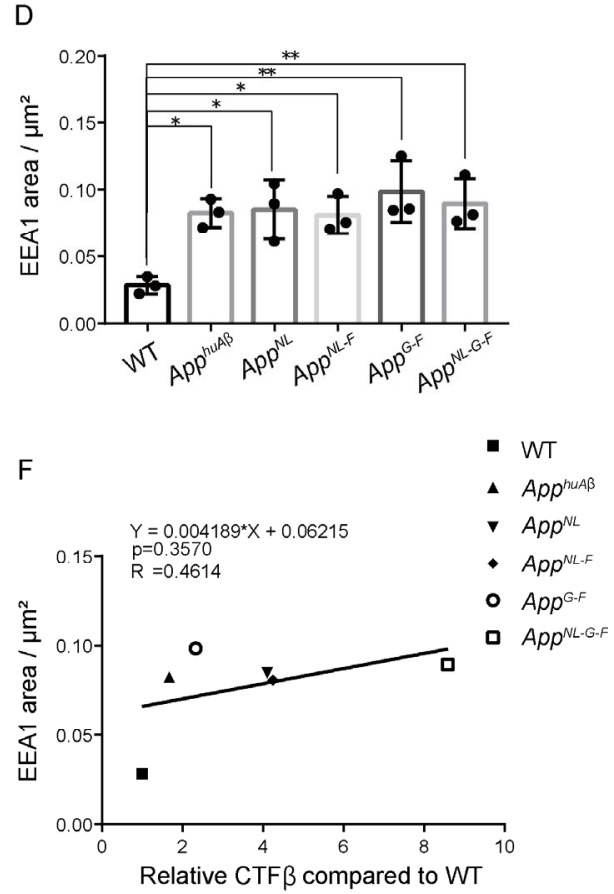

Figure 4. APP CTF expression levels and endosome abnormalities

(A) APP CTF expression in the brains of 12-month-old WT, $A p p^{h u A \beta}, A p p^{N L}, A p p^{N L-F}, A p p^{G-F}$ and $A p p^{N L-G-F}$ mice. See also Figures S3-S4. (B) Quantification of relative levels of APP CTF$\beta$ relative levels compared to WT. WT, $A p p^{h u A \beta}, A p p^{N L}, A p p^{N L-F}, A p p^{G-F}$ and $A p p^{N L-G-F} ; \mathrm{n}=4$ for each genotype, one-way ANOVA followed by Tukey's multiple comparison test. (C) Immunohistochemical images of early endosomes in CA1 pyramidal cells detected by EEA1 antibody (red) and Hoechst33342 staining of nuclei (blue). Brain sections from 12-month-old WT, $A p p^{h u A \beta}, A p p^{N L}, A p p^{N L-F}, A p p^{G-F}$ and $A p p^{N L-G-F}$ mice. Scale bars indicate $20 \mu \mathrm{m}$ (left) and $5 \mu \mathrm{m}$ (right), respectively for each genotype. (D) Statistical analysis of EEA1 ${ }^{+}$area per $\mu \mathrm{m}^{2}$ in pyramidal cells of hippocampal CA1 region. (E) Endosomal size distribution was statistically analyzed using MetaMorph imaging software. WT, $A p p^{h u A \beta}, A p p^{N L}, A p p^{N L-F}, A p p^{G-F}$ and $A p p^{N L-G-}$ ${ }^{F} ; \mathrm{n}=3$ for each genotype, one-way ANOVA followed by Tukey's multiple comparison test (D and E). Each bar represents the mean \pm SEM. $* P<0.05, * * P<0.01, * * * P<0.001$ (B, D and 
E). (F) Relationship between EEA1 area / $\mu \mathrm{m}^{2}$ and CTF- $\beta$ content. Pearson's correlation coefficient $\mathrm{R}$, the associated $\mathrm{p}$ value and linear regression equation are shown in the figure.

\section{Table 1. Isogenic panel of mouse lines used in the present study}

1. $A p p^{W T}$ line

2. $A p p^{h A \beta}$ line (App knock-in mice with $\mathrm{A} \beta$ sequence humanized)

3. $A p p^{N L}$ line (App knock-in mice carrying Swedish mutations)

4. $A p p^{N L-F}$ line (App knock-in mice carrying Swedish and Iberian mutations)

5. $A p p^{G-F}$ line (App knock-in mice carrying Arctic and Iberian mutations)

6. $A p p^{N L-G-F}$ line (App knock-in mice carrying Swedish, Arctic, and Iberian mutations)

\section{REFERENCES}

1. Alzheimer, A., Stelzmann, R.A., Schnitzlein, H.N. \& Murtagh, F.R. An English translation of Alzheimer's 1907 paper, "Uber eine eigenartige Erkankung der Hirnrinde". Clin Anat 8, 429431 (1995).

2. Sevigny, J., et al. The antibody aducanumab reduces Abeta plaques in Alzheimer's disease. Nature 537, 50-56 (2016).

3. Sasaguri, H., et al. APP mouse models for Alzheimer's disease preclinical studies. Embo $j$ 36, 2473-2487 (2017).

4. Saito, T., et al. Single App knock-in mouse models of Alzheimer's disease. Nat Neurosci 17, $661-663$ (2014).

5. Li, S., et al. Swedish mutant APP-based BACE1 binding site peptide reduces APP B-cleavage and cerebral AB levels in Alzheimer's mice. Sci Rep 5, 11322 (2015).

6. Kwart, D., et al. A Large Panel of Isogenic APP and PSEN1 Mutant Human iPSC Neurons Reveals Shared Endosomal Abnormalities Mediated by APP B-CTFs, Not AB. Neuron 104, 256270.e255 (2019).

7. Lauritzen, I., et al. Intraneuronal aggregation of the B-CTF fragment of APP (C99) induces ABindependent lysosomal-autophagic pathology. Acta Neuropathol 132, 257-276 (2016).

8. Cataldo, A.M., et al. Endocytic pathway abnormalities precede amyloid beta deposition in 
sporadic Alzheimer's disease and Down syndrome: differential effects of APOE genotype and presenilin mutations. Am J Pathol 157, 277-286 (2000).

9. Rogaeva, E., et al. The neuronal sortilin-related receptor SORL1 is genetically associated with Alzheimer disease. Nat Genet 39, 168-177 (2007).

10. Israel, M.A., et al. Probing sporadic and familial Alzheimer's disease using induced pluripotent stem cells. Nature 482, 216-220 (2012).

11. Small, S.A., Simoes-Spassov, S., Mayeux, R. \& Petsko, G.A. Endosomal Traffic Jams Represent a Pathogenic Hub and Therapeutic Target in Alzheimer's Disease. Trends Neurosci 40, 592602 (2017).

12. Toh, W.H. \& Gleeson, P.A. Dysregulation of intracellular trafficking and endosomal sorting in Alzheimer's disease: controversies and unanswered questions. Biochem $J$ 473, 1977-1993 (2016).

13. Garneau, J.E., et al. The CRISPR/Cas bacterial immune system cleaves bacteriophage and plasmid DNA. Nature 468, 67-71 (2010).

14. Komor, A.C., Badran, A.H. \& Liu, D.R. CRISPR-Based Technologies for the Manipulation of Eukaryotic Genomes. Cell 169, 559 (2017).

15. Scott, J.D., et al. Discovery of the 3-Imino-1,2,4-thiadiazinane 1,1-Dioxide Derivative Verubecestat (MK-8931)-A B-Site Amyloid Precursor Protein Cleaving Enzyme 1 Inhibitor for the Treatment of Alzheimer's Disease. J Med Chem 59, 10435-10450 (2016).

16. Kennedy, M.E., et al. The BACE1 inhibitor verubecestat (MK-8931) reduces CNS beta-amyloid in animal models and in Alzheimer's disease patients. Sci Transl Med 8, 363ra150 (2016).

17. Cradick, T.J., Qiu, P., Lee, C.M., Fine, E.J. \& Bao, G. COSMID: A Web-based Tool for Identifying and Validating CRISPR/Cas Off-target Sites. Mol Ther Nucleic Acids 3, e214 (2014).

18. Bae, S., Park, J. \& Kim, J.S. Cas-OFFinder: a fast and versatile algorithm that searches for potential off-target sites of Cas9 RNA-guided endonucleases. Bioinformatics 30, 1473-1475 (2014).

19. Yamakawa, H., Yagishita, S., Futai, E. \& Ishiura, S. beta-Secretase inhibitor potency is decreased by aberrant beta-cleavage location of the "Swedish mutant" amyloid precursor protein. J Biol Chem 285, 1634-1642 (2010).

20. Hussain, I., et al. Oral administration of a potent and selective non-peptidic BACE-1 inhibitor decreases beta-cleavage of amyloid precursor protein and amyloid-beta production in vivo. $J$ Neurochem 100, 802-809 (2007).

21. Rabe, S., et al. The Swedish APP mutation alters the effect of genetically reduced BACE1 
expression on the APP processing. J Neurochem 119, 231-239 (2011).

22. Kalimo, H., et al. The Arctic AbetaPP mutation leads to Alzheimer's disease pathology with highly variable topographic deposition of differentially truncated Abeta. Acta Neuropathol Commun 1, 60 (2013).

23. Hung, C.O.Y. \& Livesey, F.J. Altered $\mathrm{Y}^{-}$Secretase Processing of APP Disrupts Lysosome and Autophagosome Function in Monogenic Alzheimer's Disease. Cell Rep 25, 3647-3660.e3642 (2018).

24. Jiang, Y., et al. Alzheimer's-related endosome dysfunction in Down syndrome is Abetaindependent but requires APP and is reversed by BACE-1 inhibition. Proc Natl Acad Sci US A 107, 1630-1635 (2010).

25. Kim, S., et al. Evidence that the rab5 effector APPL1 mediates APP-BCTF-induced dysfunction of endosomes in Down syndrome and Alzheimer's disease. Mol Psychiatry 21, 707-716 (2016).

26. Woodruff, G., et al. Defective Transcytosis of APP and Lipoproteins in Human iPSC-Derived Neurons with Familial Alzheimer's Disease Mutations. Cell Rep 17, 759-773 (2016).

27. Xu, W., et al. Amyloid precursor protein-mediated endocytic pathway disruption induces axonal dysfunction and neurodegeneration. J Clin Invest 126, 1815-1833 (2016).

28. Treusch, S., et al. Functional links between AB toxicity, endocytic trafficking, and Alzheimer's disease risk factors in yeast. Science 334, 1241-1245 (2011).

29. Willen, K., et al. Abeta accumulation causes MVB enlargement and is modelled by dominant negative VPS4A. Mol Neurodegener 12, 61 (2017).

30. Marshall, K.E., Vadukul, D.M., Staras, K. \& Serpell, L.C. Misfolded amyloid-8-42 impairs the endosomal-lysosomal pathway. Cell Mol Life Sci (2020).

31. Baglietto-Vargas, D., et al. Generation of a humanized Abeta expressing mouse demonstrating aspects of Alzheimer's disease-like pathology. Nat Commun 12, 2421 (2021).

32. Knupp, A., et al. Depletion of the AD Risk Gene SORL1 Selectively Impairs Neuronal Endosomal Traffic Independent of Amyloidogenic APP Processing. Cell Rep 31, 107719 (2020).

33. Pensalfini, A., et al. Endosomal Dysfunction Induced by Directly Overactivating Rab5 Recapitulates Prodromal and Neurodegenerative Features of Alzheimer's Disease. Cell Rep 33, $108420(2020)$.

34. Jonsson, T., et al. A mutation in APP protects against Alzheimer's disease and age-related cognitive decline. Nature 488, 96-99 (2012).

35. Elvang, A.B., et al. Differential effects of gamma-secretase and BACE1 inhibition on brain Abeta levels in vitro and in vivo. J Neurochem 110, 1377-1387 (2009). 
bioRxiv preprint doi: https://doi.org/10.1101/2021.08.22.457278; this version posted August 24,2021 . The copyright holder for this preprint

(which was not certified by peer review) is the author/funder, who has granted bioRxiv a license to display the preprint in perpetuity. It is made available under aCC-BY-NC 4.0 International license.

36. Hsu, P.D., et al. DNA targeting specificity of RNA-guided Cas9 nucleases. Nat Biotechnol 31, 827-832 (2013).

37. Yang, H., Wang, H. \& Jaenisch, R. Generating genetically modified mice using CRISPR/Casmediated genome engineering. Nat Protoc 9, 1956-1968 (2014). 


\section{SUPPLEMENTARY INFORMATION}

\section{An isogenic panel of single App knock-in mouse models of Alzheimer's disease confers differential profiles of $\beta$-secretase inhibition and endosomal abnormalities}

Naoto Watamura ${ }^{1}$, Kaori Sato ${ }^{1,2}$, Gen Shiihashi ${ }^{3}$, Ayami Iwasaki ${ }^{4}$, Naoko Kamano ${ }^{1}$, Mika

Takahashi $^{1}$, Misaki Sekiguchi ${ }^{1}$, Naomi Yamazaki ${ }^{1}$, Ryo Fujioka ${ }^{1}$, Kenichi Nagata ${ }^{3}$, Shoko Hashimoto $^{1}$, Takashi Saito ${ }^{1,4}$, Toshio Ohshima ${ }^{2}$, Takaomi C. Saido ${ }^{1 *}$ and Hiroki Sasaguri ${ }^{{ }^{*}}$

${ }^{1}$ Laboratory for Proteolytic Neuroscience, RIKEN Center for Brain Science, 2-1 Hirosawa, Wako, Saitama 351-0198, Japan

${ }^{2}$ Laboratory for Molecular Brain Science, Department of Life Science and Medical Bioscience, Waseda University, Shinjuku, Tokyo 162-8480, Japan

${ }^{3}$ Neurological Institute, Shonan Keiiku Hospital, 4360 Endo, Fujisawa, Kanagawa, 252-0816, Japan

${ }^{4}$ Yamaguchi University School of Medicine, 1-1-1 Minamikogushi, Ube, Yamaguchi, 755-8505, Japan

${ }^{5}$ Department of Functional Anatomy and Neuroscience, Nagoya University Graduate School of Medicine, Nagoya, Aichi 466-8550, Japan

${ }^{6}$ Department of Neurocognitive Science, Institute of Brain Science, Nagoya City University Graduate School of Medical Sciences, Nagoya, Aichi 467-8601, Japan 
bioRxiv preprint doi: https://doi.org/10.1101/2021.08.22.457278; this version posted August 24, 2021. The copyright holder for this preprint

(which was not certified by peer review) is the author/funder, who has granted bioRxiv a license to display the preprint in perpetuity. It is made available under aCC-BY-NC 4.0 International license.

\section{Supplemental Figure 1}

\section{A}

$\underline{A p p \operatorname{Ex} 16}$

$A \beta 42$

WT

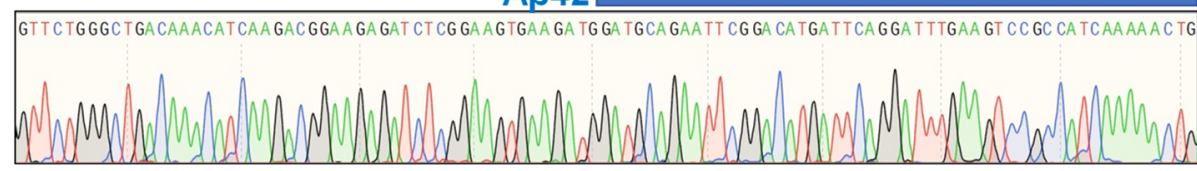

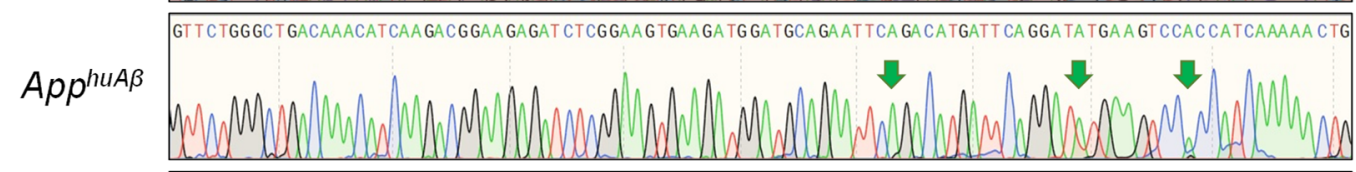

GTTCTGGGCTGACAAACAT CAA GACGGAA GA GATCTCGGAA GT AATCTA GATGCA GAATTCA GACATGATT CA GGA TATGAAGTC CACCATCAAAAACTG
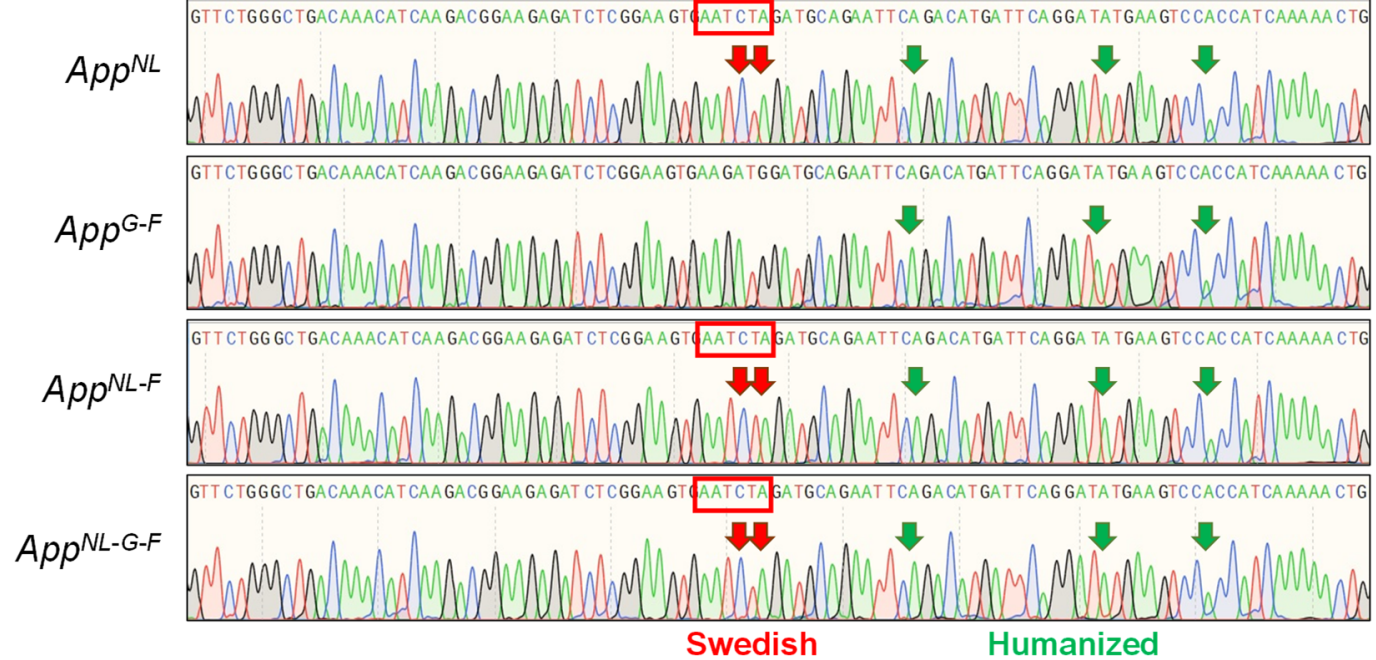

$\mathrm{B}$

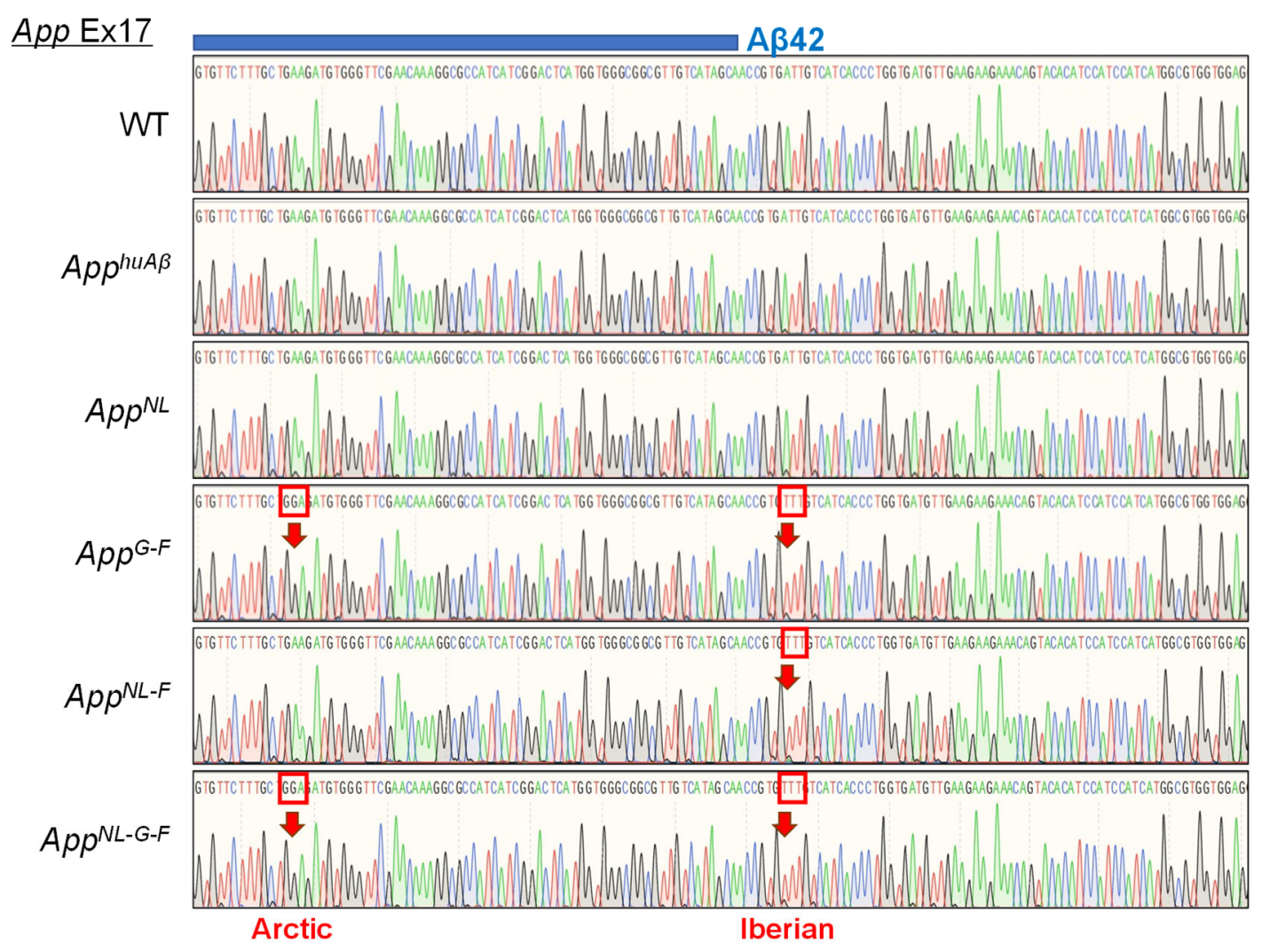


C

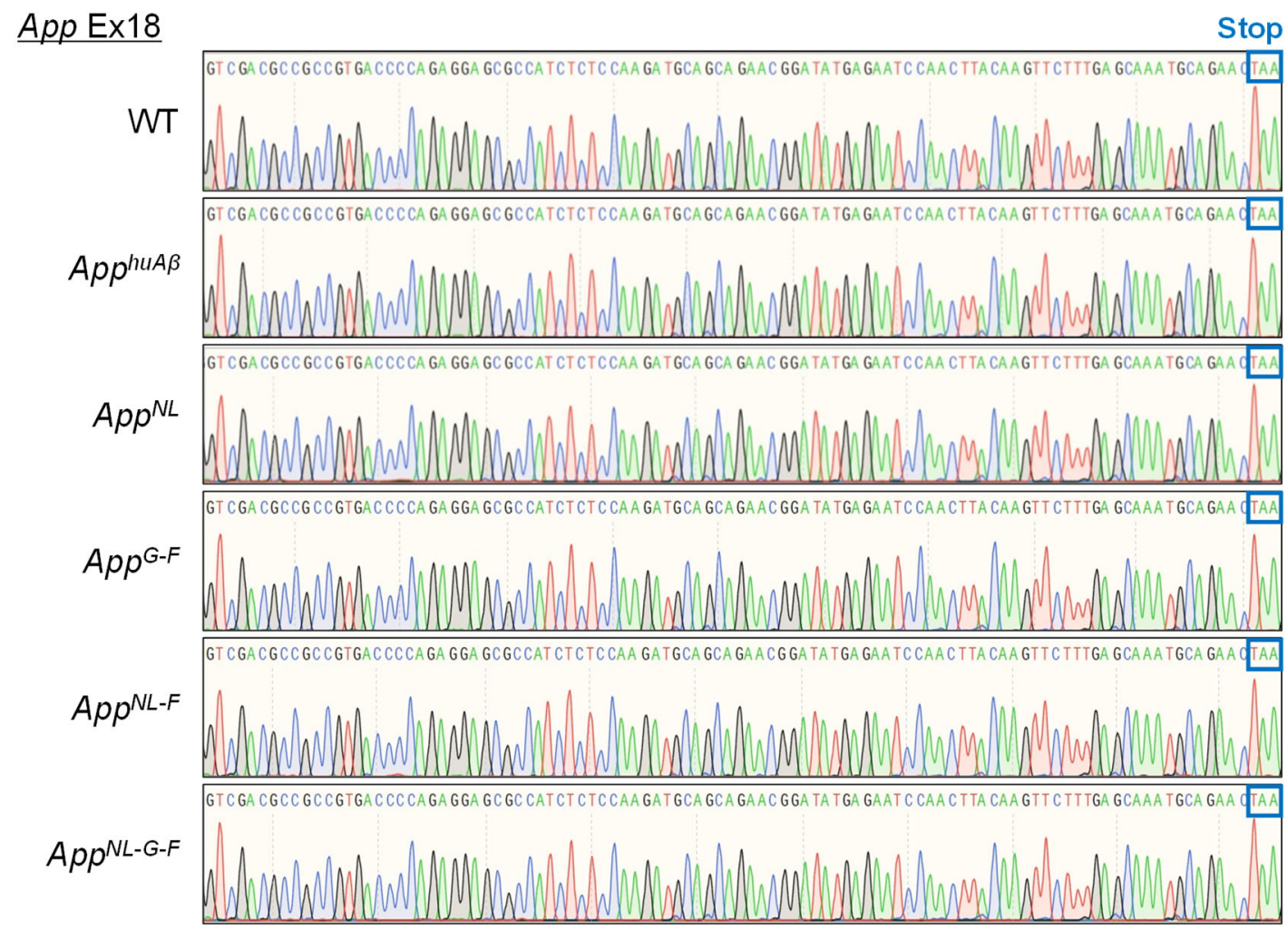

Figure S1. Exon sequences of the App gene in App knock-in mouse lines encoding CTF- $\beta$.

Sequencing analyses of App exon 16 (A), exon 17 (B) and exon 18 (C) indicate that all genotypes of the App knock-in mice (Table 1) share identical amino acid sequences except for the artificially introduced mutations, indicating that the difference in the electrophoretic mobility of CTF- $\beta$ between each line shown in Fig. 4a can be solely attributed to the intentionally altered mutations introduced. 


\section{Supplemental Figure 2}

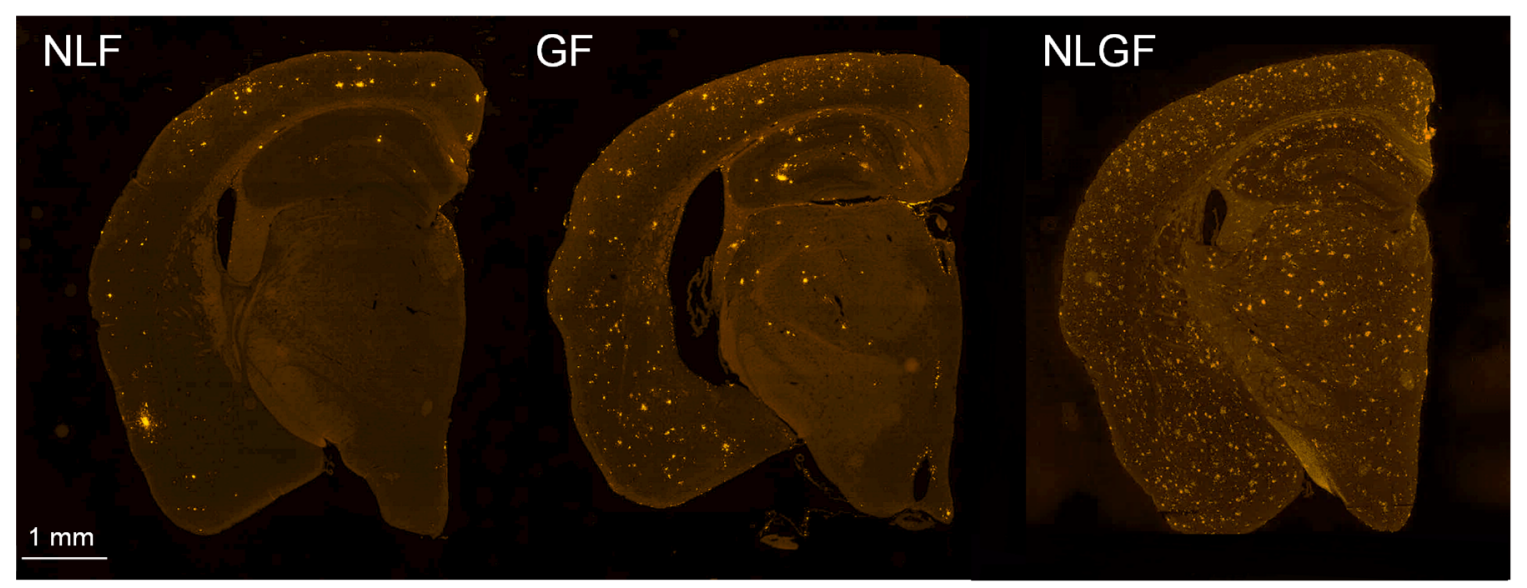

Figure S2. A $\beta$ plaque formation in the brains of 12-month-old $A p p^{N L-F}, A_{p p}^{G-F}$ and $A p p^{N L-G-F}$ mice. Immunohistochemistry images with N1D antibody detection show that $A p p^{G-F}$ mice exhibited more and less prominent amyloid pathology than $A p p^{N L-F}$ and $A p p^{N L-G-F}$ mice, respectively, at 12 months. 
bioRxiv preprint doi: https://doi.org/10.1101/2021.08.22.457278; this version posted August 24, 2021. The copyright holder for this preprint (which was not certified by peer review) is the author/funder, who has granted bioRxiv a license to display the preprint in perpetuity. It is made available under aCC-BY-NC 4.0 International license.

\section{Supplemental Figure 3}

A

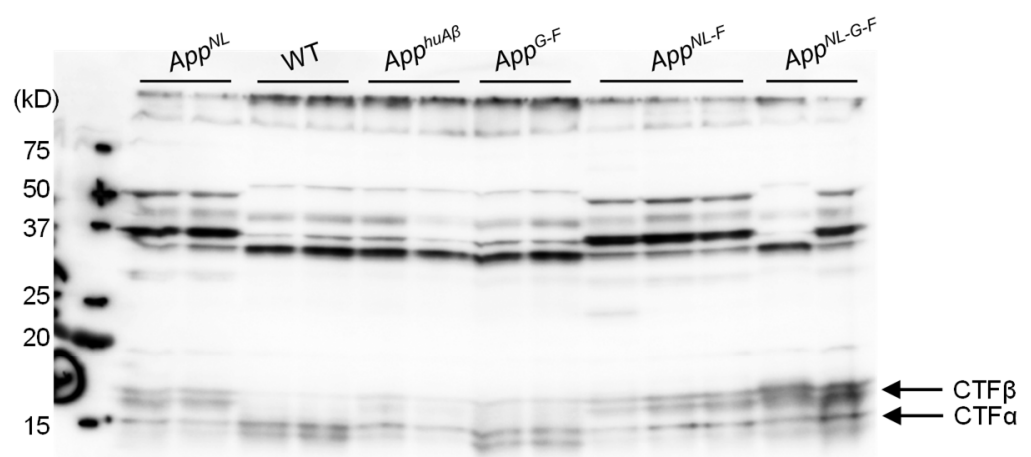

B

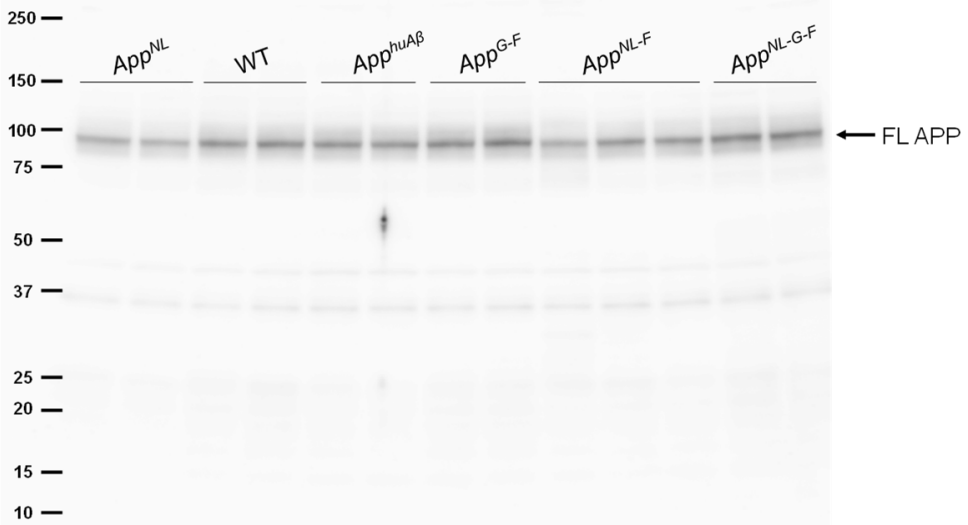

C

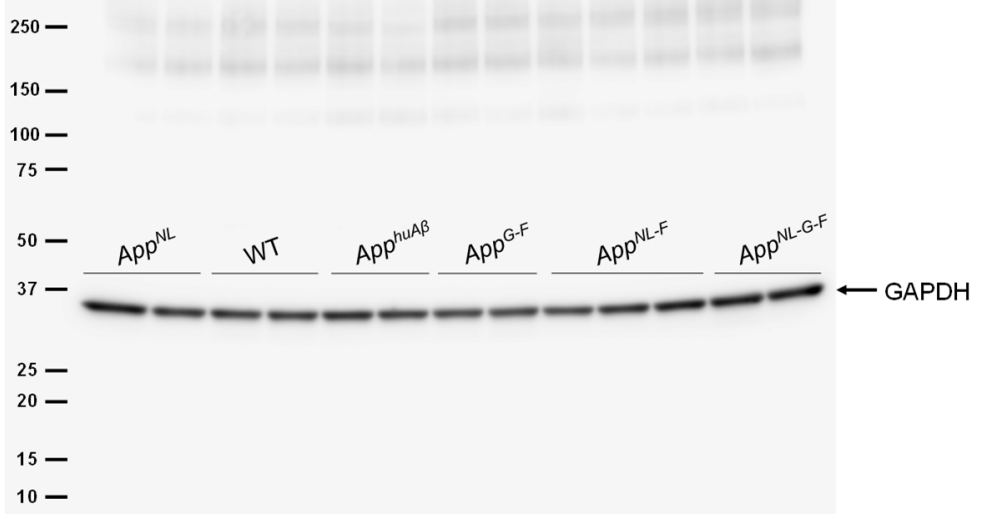


D

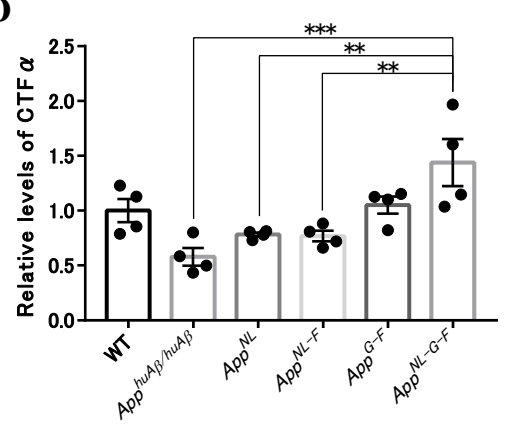

$\mathbf{E}$

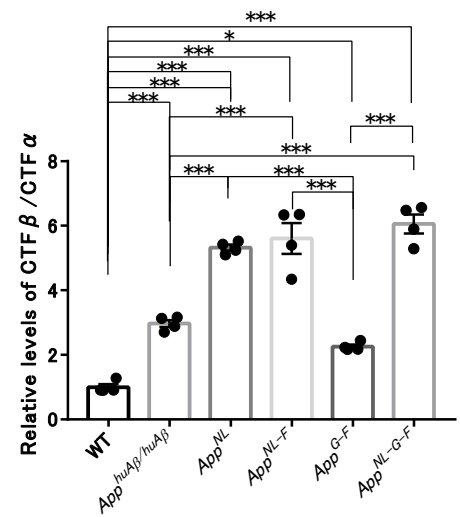

$\mathbf{F}$

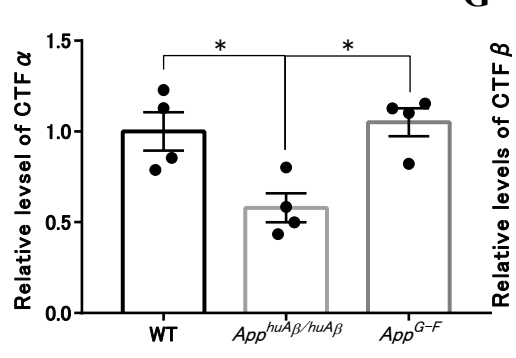

G

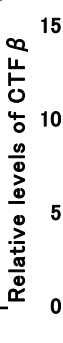

H o

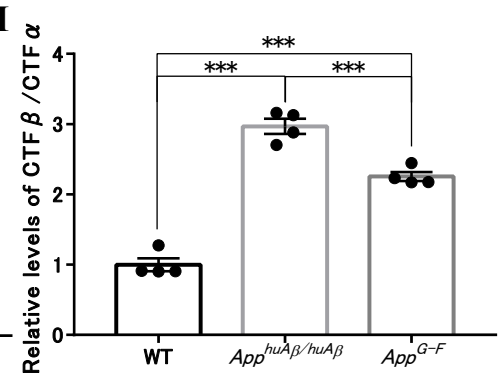

Figure S3. Western blot analysis of APP CTFs.

(A-C) Full-blots of APP CTFs (A) and full-length APP (B) and GAPDH (C) using the cortices of 12month-old $A p p$-knock-in lines used in Figure 4 are shown. (D) Intensities of CTF- $\alpha$-immunoreactive bands were quantified and statistically analyzed for WT, $A p p^{h u A \beta}, A p p^{N L}, A p p^{N L-F}, A p p^{G-F}$ and $A p p^{N L-}$ $G-F$ mice. (E) Relative levels of CTF- $\beta / C T F-\alpha$ ratio compared to WT mice. (E-G) Relative levels of CTF- $\alpha(\mathrm{F})$, CTF- $\beta(\mathrm{G})$ and CTF- $\beta / \mathrm{CTF}-\alpha$ ratios (H) were statistically analysed for WT, $A p p^{h u A \beta}$ and $A p p^{G-F}$ mice. Each bar represents the mean \pm SEM. $* P<0.05, * * P<0.01, * * * P<0.001$. (WT; $\mathrm{n}=4, A p p^{h u A \beta} ; \mathrm{n}=4, A p p^{N L} ; \mathrm{n}=4, A p p^{N L-F} ; \mathrm{n}=4, A p p^{G-F} ; \mathrm{n}=4$ and $A p p^{N L-G-F} ; \mathrm{n}=4$, one-way ANOVA followed by Turkey's multiple comparison test). 


\section{Supplemental Figure 4}
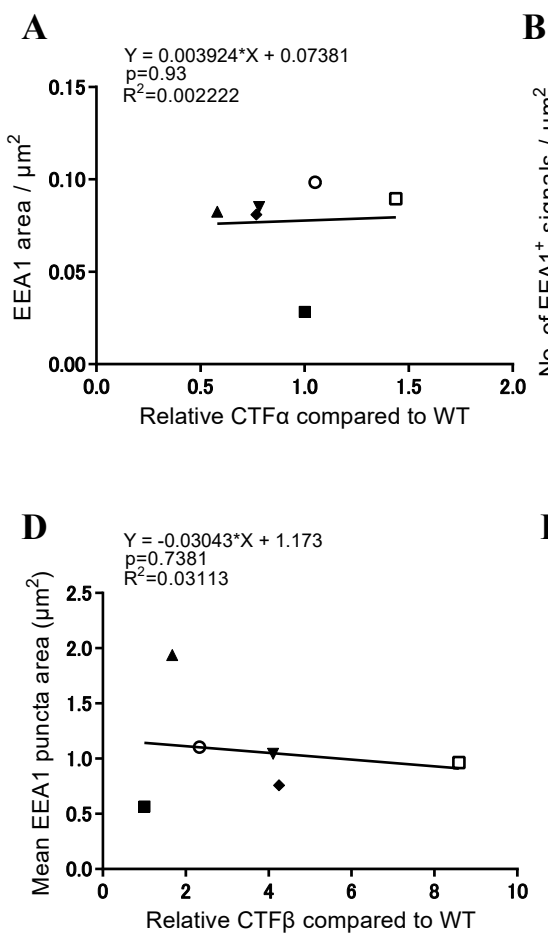

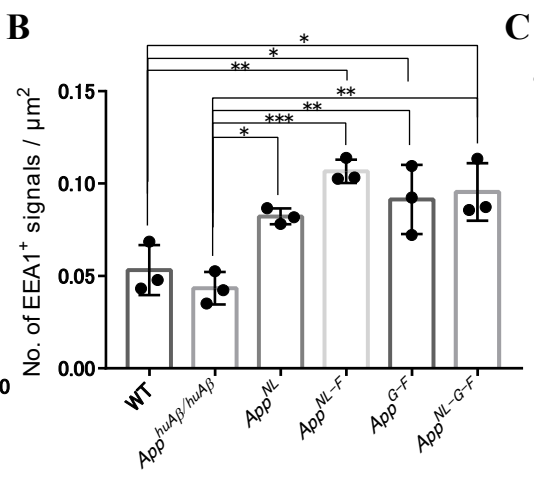

C

$\mathbf{E}$

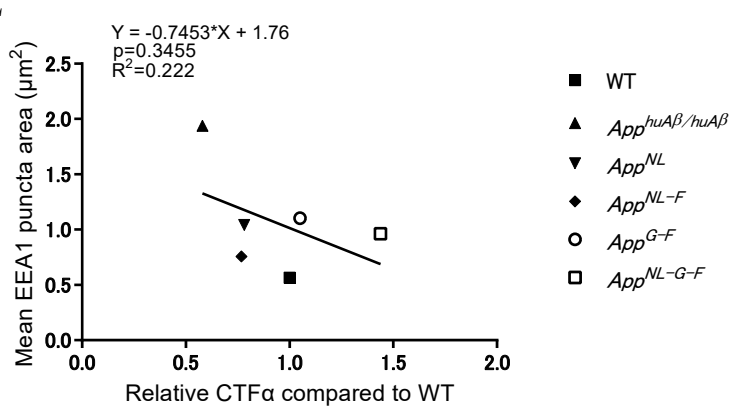

\section{Figure S4. Analysis of APP CTFs and endosomal abnormalities}

(A) CTF- $\alpha$ levels did not correlate with the area $\left(\mu \mathrm{m}^{2}\right)$ of EEA1 $1^{+}$. (B) Number of EEA1 ${ }^{+}$signals per $\mu \mathrm{m}^{2}$ was increased in App-knock-in mice except for $A p p^{h u A \beta}$ mice. (C) Mean EEA1 puncta area. (DE) No correlation was observed between mean EEA1 ${ }^{+}$puncta area and levels of CTF- $\beta$ (D) or CTF$\alpha(E)$. Pearson correlation coefficient $\mathrm{R}$ and $\mathrm{p}$ value are shown along with the linear regression equation (A), (D) and (E). Each bar represents the mean \pm SEM. $* P<0.05, * * P<0.01$, ${ }^{* * *} P<$ 0.001. (WT; n=3,App $p^{h u \beta} ; \mathrm{n}=3, A p p^{N L} ; \mathrm{n}=3, A p p^{N L-F} ; \mathrm{n}=3, A p p^{G-F} ; \mathrm{n}=3$ and $A p p^{N L-G-F} ; \mathrm{n}=3$, one-way ANOVA followed by Turkey's multiple comparison test) (B) and (C). 


\section{Supplemental Table 1}

\begin{tabular}{|c|c|}
\hline \multicolumn{2}{|l|}{ sgRNA } \\
\hline T7_sgRNA_moAPP & TGTAATACGACTCACTATAGGAAGACGGAAGAGATCTCGGA \\
\hline _NL_KM_F & AGTTTTAGTACTCTGGAAACAGAATC \\
\hline \multirow{2}{*}{$\begin{array}{l}\text { sgRNA_SaCas9_tail } \\
\text { _R }\end{array}$} & AAAAATCTCGCCAACAAGTTGACGAGATAAACACGGCATTT \\
\hline & TGCCTTGTTTTAGTAGATTCTGTTTCCAGAGTACTAAAAC \\
\hline \multicolumn{2}{|l|}{ SaCas9 mRNA } \\
\hline T7-SaCas9-F & TAATACGACTCACTATAGGGCCCCATTGACGCAAAT \\
\hline T7-SaCas9-R & GGCAACTAGAAGGCACAGTCGA \\
\hline \multicolumn{2}{|l|}{ ssODN } \\
\hline APP-Ex16- & caatctcggggagaggcagtttattttgcctacCAGTTTTTGATGGTGGACTTC \\
\hline \multirow[t]{3}{*}{ NL_KM_ssDNA } & ATATCCTGAATCATGTCTGAATTCTGCATCCATCTTCACTTC \\
\hline & CGAGATCTCTTCCGTCTTGATGTTTGTCAGCCCAGAAC \\
\hline & ctgcgtcaaacacaaagtatgcagggecatccgttagtgtgaccgccagccacaaggaggcaaa \\
\hline
\end{tabular}

Table S1.Information on primers and oligonucleotides used for the synthesis of sgRNA, SaCas9 mRNA and ssODN.

In vitro synthesis of CRISPR tools was performed with the listed primers for the generation of App $^{G-}$ $F$ and $A p p^{h u A \beta}$ mice. See Methods for details. 


\section{Supplemental Table 2}

\begin{tabular}{|l|l|}
\hline \multicolumn{2}{|l|}{ Genotyping of the App ${ }^{G-F}$ and $A p p^{\text {huA } \beta}$ mice } \\
\hline moAPP-Ex16-hs-F2 & ACAGGCATTACATATTCAGCGT \\
\hline moAPP-Ex16-hs-R2 & ACTATCAACAGAGCCCCACT \\
\hline \multicolumn{2}{|l}{} \\
\hline Off-target analysis & CCATGCATTGTCTTTGAACCT \\
\hline OFF1-F & CGCCTCTGAATTCCTTGAA \\
\hline OFF1-R & CAGGCTGTGGGATAGGTTTT \\
\hline OFF2-F & CGAGGTCAGCTTGGCTTTTA \\
\hline OFF2-R & CTGAAGAAGAGCCAGCCTCA \\
\hline OFF3-F & TCTCAGGGAATCCACCATTC \\
\hline OFF3-R & AGTAACAGCCCAGGCAGAAA \\
\hline OFF4-F & TGCTAAGACACATAAAAACAAGCA \\
\hline OFF4-R & GGACCCGAGTTTGATTCTCA \\
\hline OFF5-F & CCTGTTTCTTCGGCATGTTT \\
\hline OFF5-R & TTCTCCTTTCAGAAGATGTTTGG \\
\hline OFF6-F & TTTCAATGTTCACCCCATCC \\
\hline OFF6-R & ACGGAAGATTCCAGCTCAGA \\
\hline OFF7-F & CCAGCACTCAATGCATGTTC \\
\hline OFF7-R & GAGACGCTTTTGGACTTGCT \\
\hline OFF8-F & TTTGCCAGCTGCAGATAATTT \\
\hline OFF8-R & TCCTAGAGGAGTTTGGGGATT \\
\hline OFF9-F & GGCCAATGCAGGTAGAATGT \\
\hline OFF9-R & GCCTTTTCATATTGCCCTCA \\
\hline OFF10-F & \\
\hline OFF10-R & \\
\hline &
\end{tabular}

Table S2. List of primers used for the genotyping and off-target analyses.

All primer pairs were used for PCR and subsequence sequencing analyses. The sequential number of the OFF primers corresponds to that of the potential off-target sites shown in Figure 1. See Methods for details. 


\section{Supplemental Table 3}

\begin{tabular}{|l|l|l|}
\hline Antibody & Dilution ratio & \# Manufacturer or reference \\
\hline A $\beta 40$ & $1: 100$ & $\# 10047$, IBL \\
\hline A 342 & $1: 100$ & $\# 18582$, IBL \\
\hline A $33 p E$ & $1: 400$ & Saido et al., 1996 \\
\hline N1D & $1: 200$ & Saido et al., 1996 \\
\hline 82E1 & $1: 500$ & $\# 10326$, IBL \\
\hline EEA1 & $1: 100$ & \#3288, Cell Signaling \\
\hline Iba1 & $1: 200$ & $\# 013-27691$, Wako \\
\hline GFAP & $1: 200$ & \#MAB3402, Millipore \\
\hline PSD-95 & $1: 50$ & \#124011, Synaptic Systems \\
\hline synaptophysin & $1: 200$ & \#61012, PROGEN \\
\hline
\end{tabular}

Table S3. List of primary antibodies used for immunohistochemistry.

Primary antibody dilution ratios are shown. See Methods for details. 


\section{SUPPLEMENTARY INFORMATION}

\section{An isogenic panel of single App knock-in mouse models of Alzheimer's disease confers differential profiles of $\beta$-secretase inhibition and endosomal abnormalities}

Naoto Watamura ${ }^{1}$, Kaori Sato ${ }^{1,2}$, Gen Shiihashi ${ }^{3}$, Ayami Iwasaki ${ }^{4}$, Naoko Kamano ${ }^{1}$, Mika

Takahashi $^{1}$, Misaki Sekiguchi ${ }^{1}$, Naomi Yamazaki ${ }^{1}$, Ryo Fujioka ${ }^{1}$, Kenichi Nagata ${ }^{3}$, Shoko Hashimoto $^{1}$, Takashi Saito ${ }^{1,4}$, Toshio Ohshima ${ }^{2}$, Takaomi C. Saido ${ }^{1 *}$ and Hiroki Sasaguri ${ }^{{ }^{*}}$

${ }^{1}$ Laboratory for Proteolytic Neuroscience, RIKEN Center for Brain Science, 2-1 Hirosawa, Wako, Saitama 351-0198, Japan

${ }^{2}$ Laboratory for Molecular Brain Science, Department of Life Science and Medical Bioscience, Waseda University, Shinjuku, Tokyo 162-8480, Japan

${ }^{3}$ Neurological Institute, Shonan Keiiku Hospital, 4360 Endo, Fujisawa, Kanagawa, 252-0816, Japan

${ }^{4}$ Yamaguchi University School of Medicine, 1-1-1 Minamikogushi, Ube, Yamaguchi, 755-8505, Japan

${ }^{5}$ Department of Functional Anatomy and Neuroscience, Nagoya University Graduate School of Medicine, Nagoya, Aichi 466-8550, Japan

${ }^{6}$ Department of Neurocognitive Science, Institute of Brain Science, Nagoya City University Graduate School of Medical Sciences, Nagoya, Aichi 467-8601, Japan 
bioRxiv preprint doi: https://doi.org/10.1101/2021.08.22.457278; this version posted August 24, 2021. The copyright holder for this preprint

(which was not certified by peer review) is the author/funder, who has granted bioRxiv a license to display the preprint in perpetuity. It is made available under aCC-BY-NC 4.0 International license.

\section{Supplemental Figure 1}

\section{A}

$\underline{A p p \operatorname{Ex} 16}$

$A \beta 42$

WT

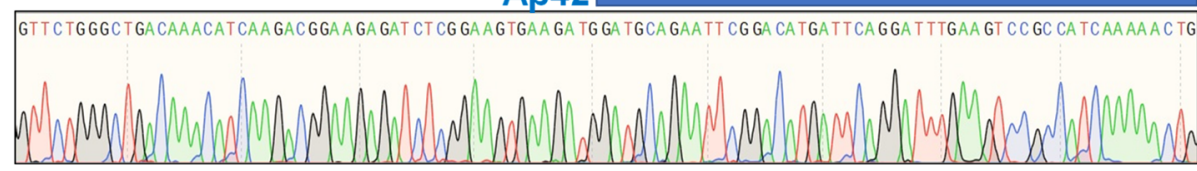

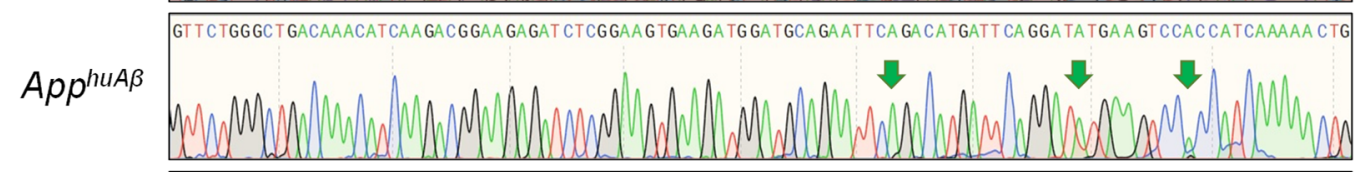

GTTCTGGGCTGACAAACAT CAA GACGGAA GA GATCTCGGAA GT AATCTA GATGCA GAATTCA GACATGATT CA GGA TATGAAGTC CACCATCAAAAACTG
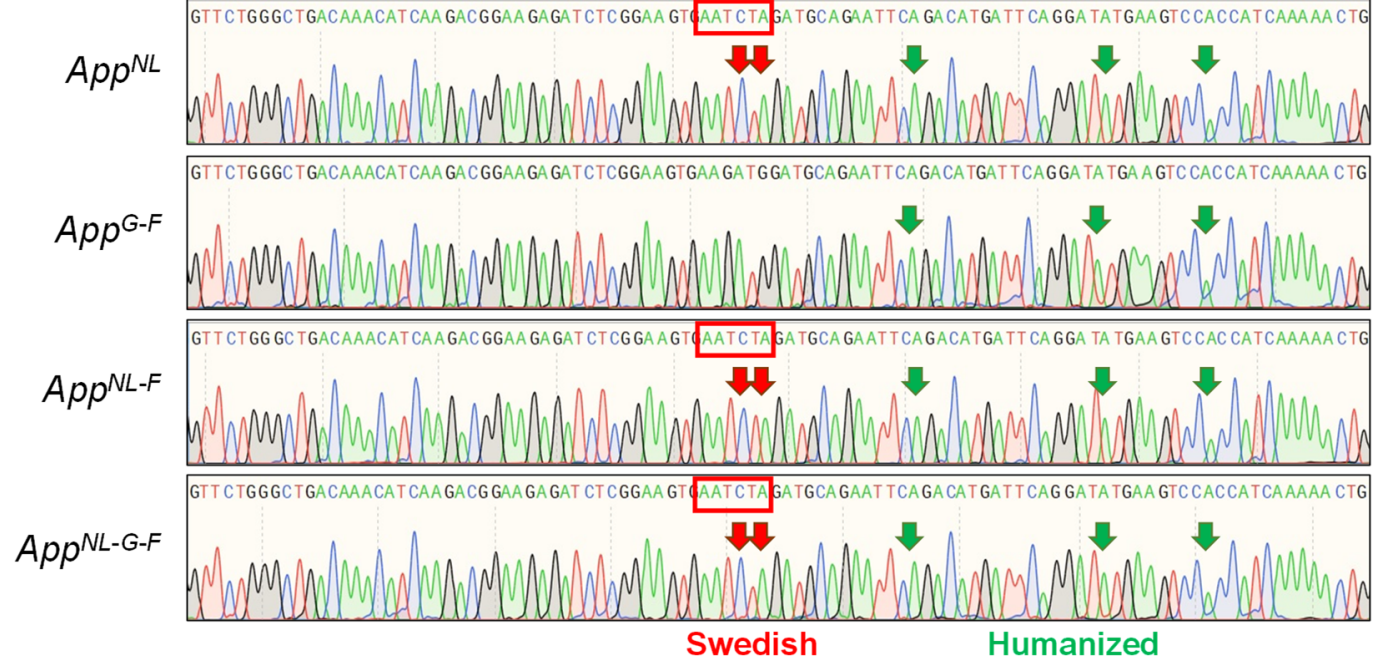

$\mathrm{B}$

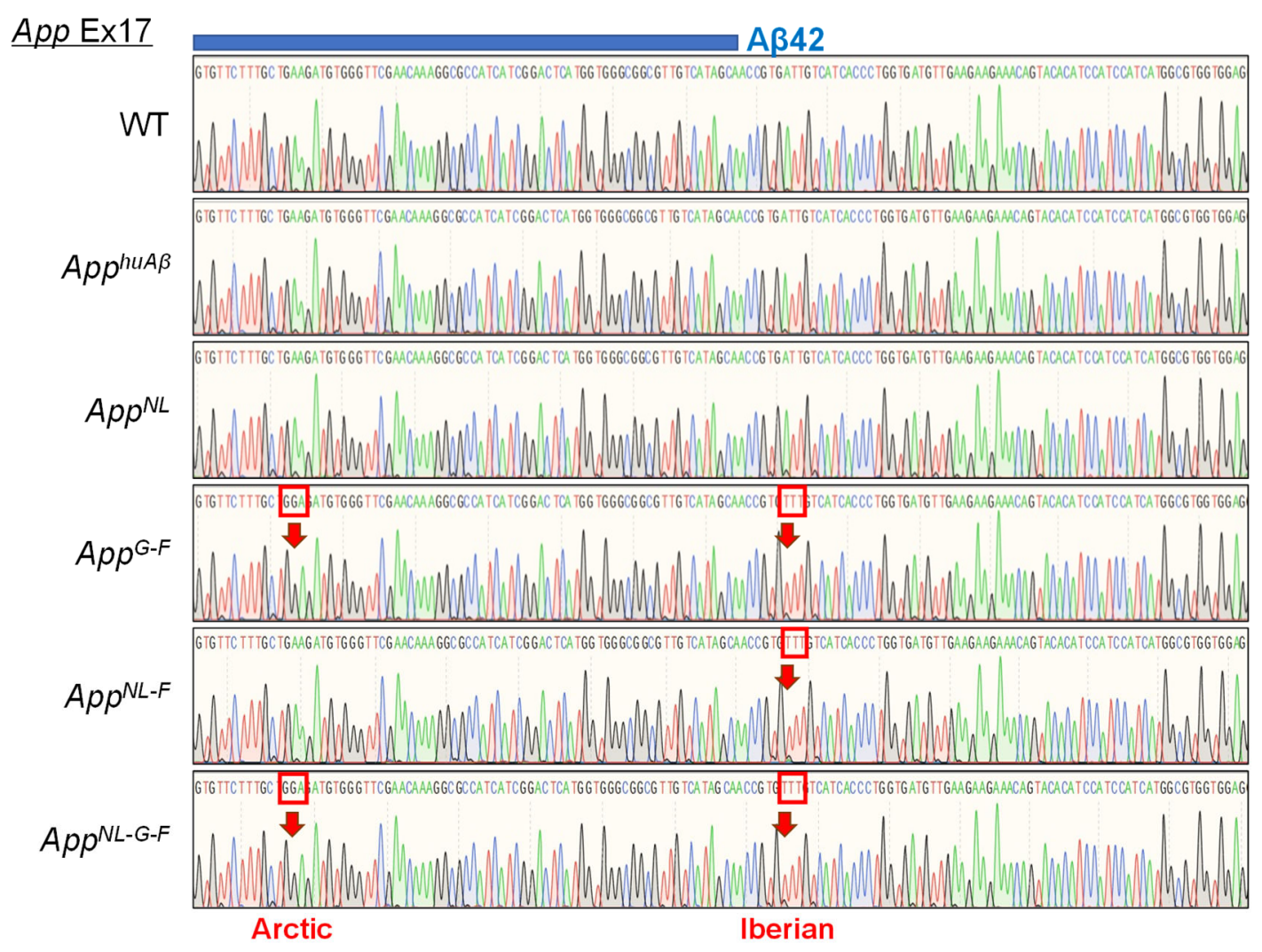


C

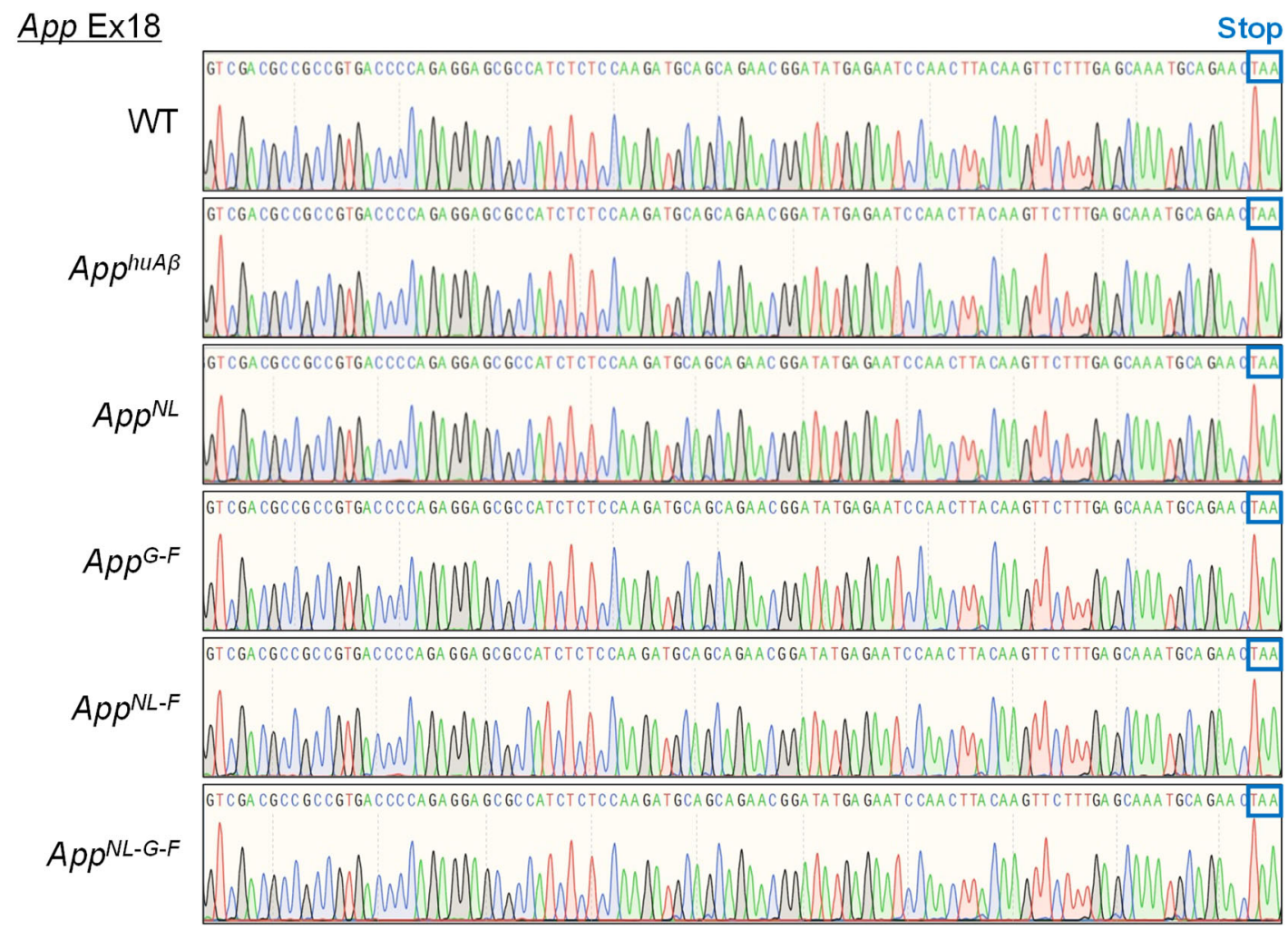

Figure S1. Exon sequences of the App gene in App knock-in mouse lines encoding CTF- $\beta$.

Sequencing analyses of App exon 16 (A), exon 17 (B) and exon 18 (C) indicate that all genotypes of the App knock-in mice (Table 1) share identical amino acid sequences except for the artificially introduced mutations, indicating that the difference in the electrophoretic mobility of CTF- $\beta$ between each line shown in Fig. 4a can be solely attributed to the intentionally altered mutations introduced. 


\section{Supplemental Figure 2}

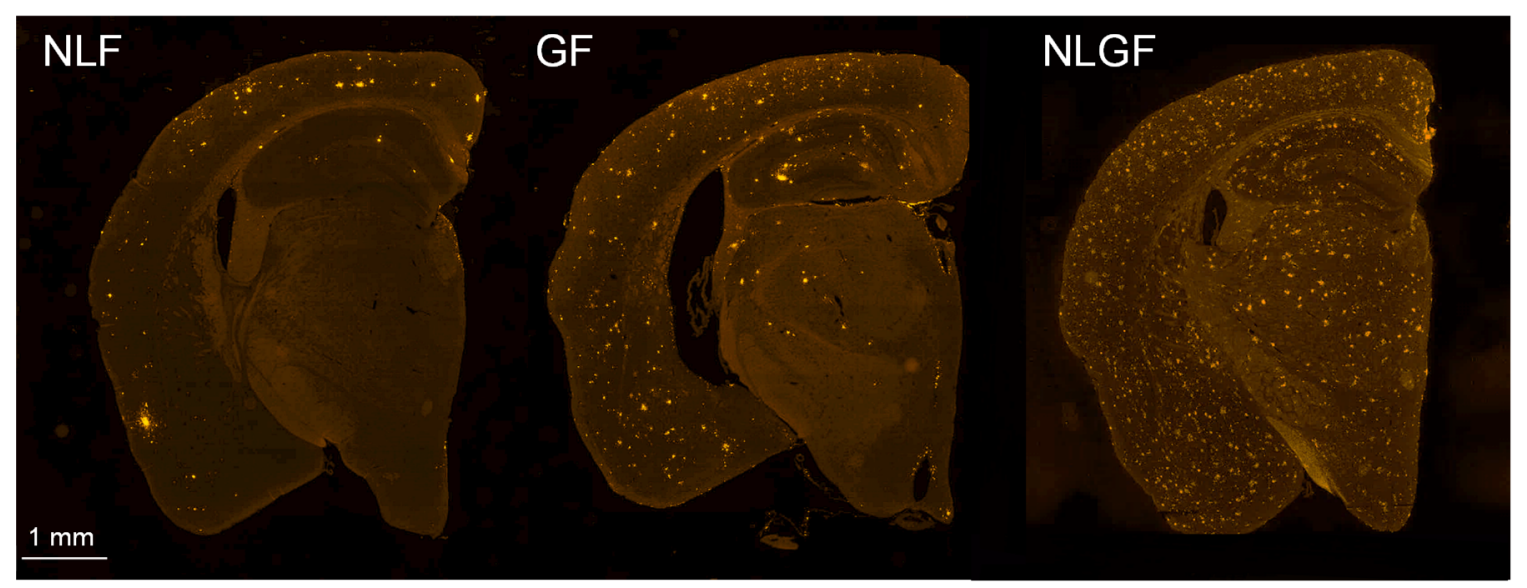

Figure S2. A $\beta$ plaque formation in the brains of 12-month-old $A p p^{N L-F}, A_{p p}^{G-F}$ and $A p p^{N L-G-F}$ mice. Immunohistochemistry images with N1D antibody detection show that $A p p^{G-F}$ mice exhibited more and less prominent amyloid pathology than $A p p^{N L-F}$ and $A p p^{N L-G-F}$ mice, respectively, at 12 months. 
bioRxiv preprint doi: https://doi.org/10.1101/2021.08.22.457278; this version posted August 24, 2021. The copyright holder for this preprint (which was not certified by peer review) is the author/funder, who has granted bioRxiv a license to display the preprint in perpetuity. It is made available under aCC-BY-NC 4.0 International license.

\section{Supplemental Figure 3}

A

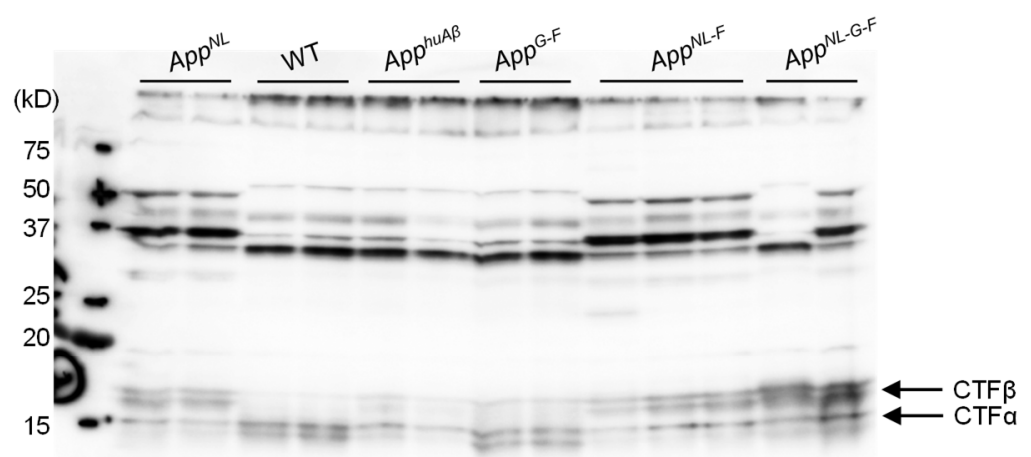

B

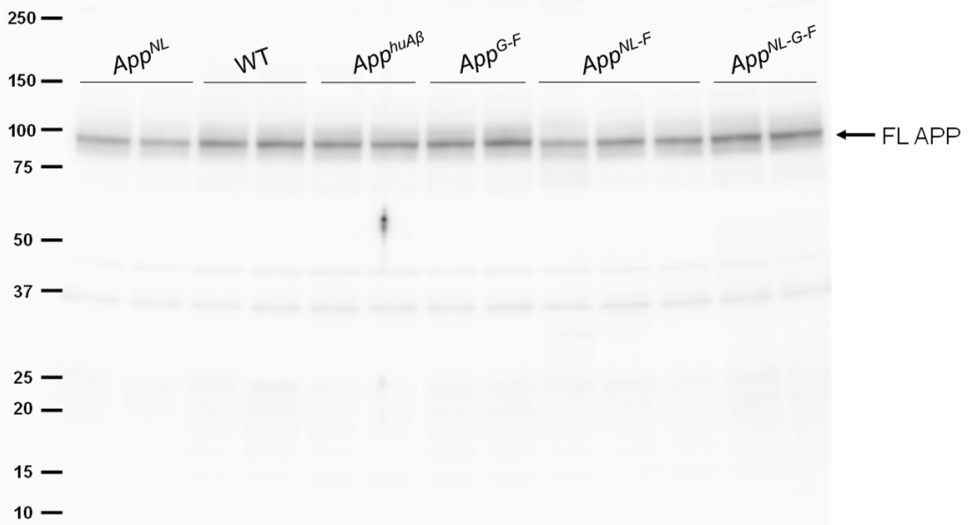

C

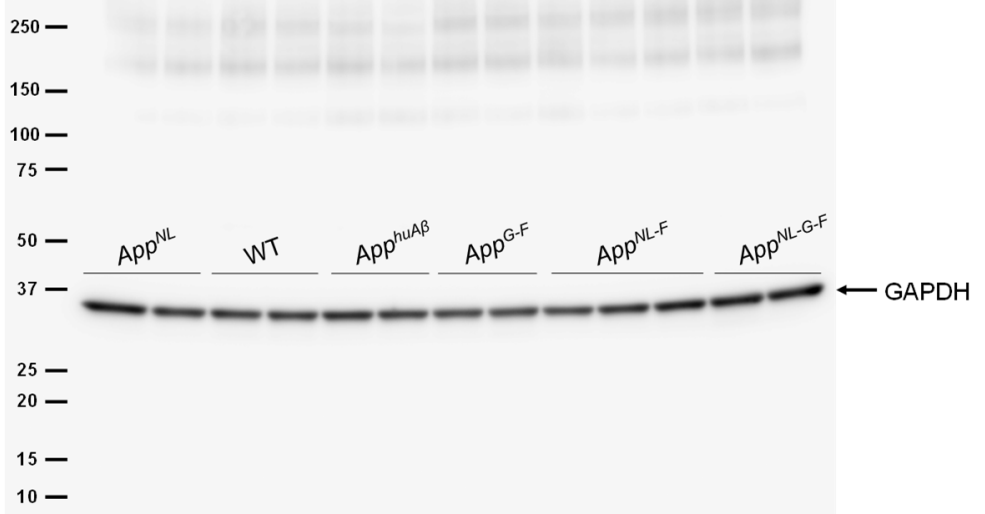


D

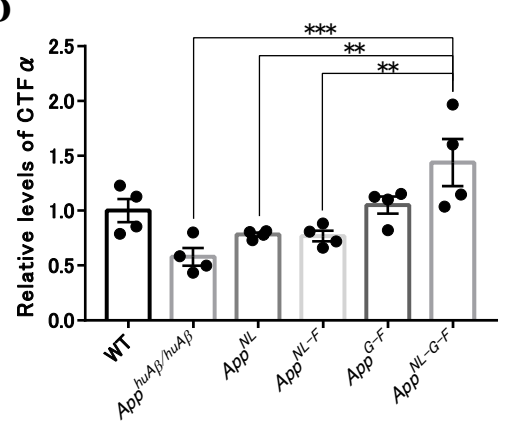

$\mathbf{E}$

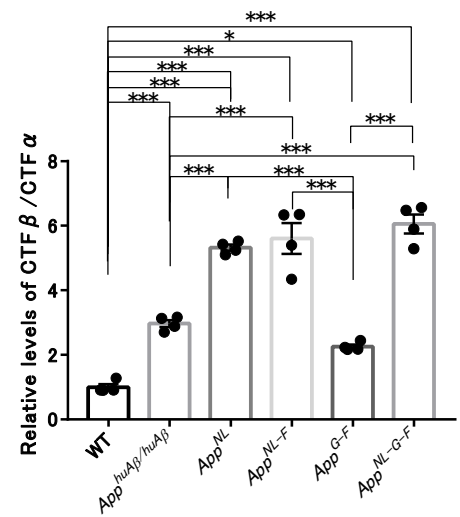

$\mathbf{F}$

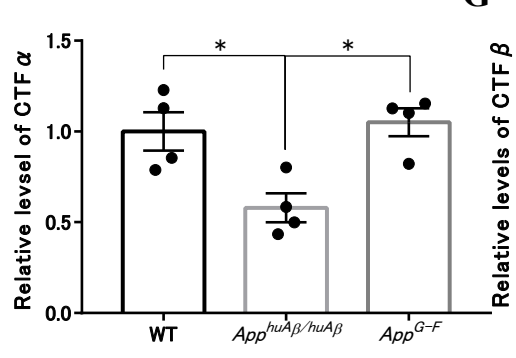

G

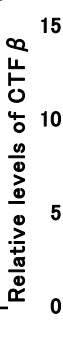

H o

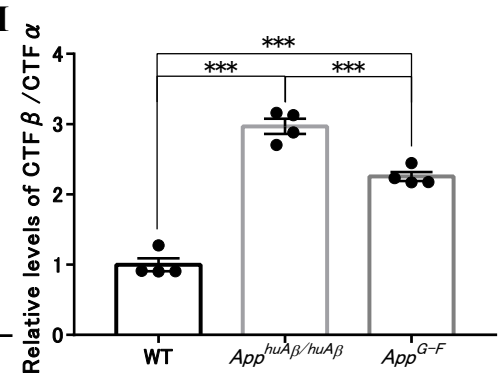

Figure S3. Western blot analysis of APP CTFs.

(A-C) Full-blots of APP CTFs (A) and full-length APP (B) and GAPDH (C) using the cortices of 12month-old $A p p$-knock-in lines used in Figure 4 are shown. (D) Intensities of CTF- $\alpha$-immunoreactive bands were quantified and statistically analyzed for WT, $A p p^{h u A \beta}, A p p^{N L}, A p p^{N L-F}, A p p^{G-F}$ and $A p p^{N L-}$ $G-F$ mice. (E) Relative levels of CTF- $\beta / C T F-\alpha$ ratio compared to WT mice. (E-G) Relative levels of CTF- $\alpha(\mathrm{F})$, CTF- $\beta(\mathrm{G})$ and CTF- $\beta / \mathrm{CTF}-\alpha$ ratios (H) were statistically analysed for WT, $A p p^{h u A \beta}$ and $A p p^{G-F}$ mice. Each bar represents the mean \pm SEM. $* P<0.05, * * P<0.01, * * * P<0.001$. (WT; $\mathrm{n}=4, A p p^{h u A \beta} ; \mathrm{n}=4, A p p^{N L} ; \mathrm{n}=4, A p p^{N L-F} ; \mathrm{n}=4, A p p^{G-F} ; \mathrm{n}=4$ and $A p p^{N L-G-F} ; \mathrm{n}=4$, one-way ANOVA followed by Turkey's multiple comparison test). 


\section{Supplemental Figure 4}
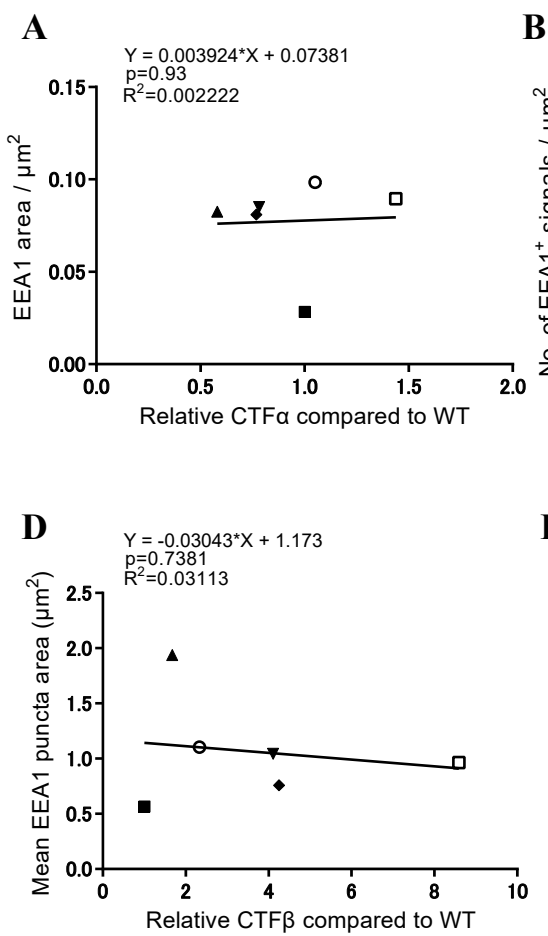

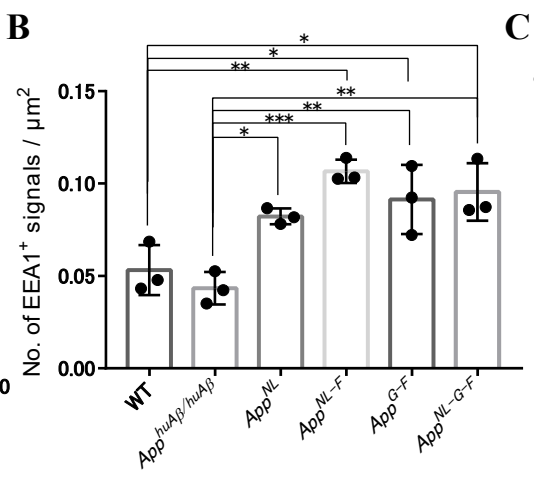

C

$\mathbf{E}$

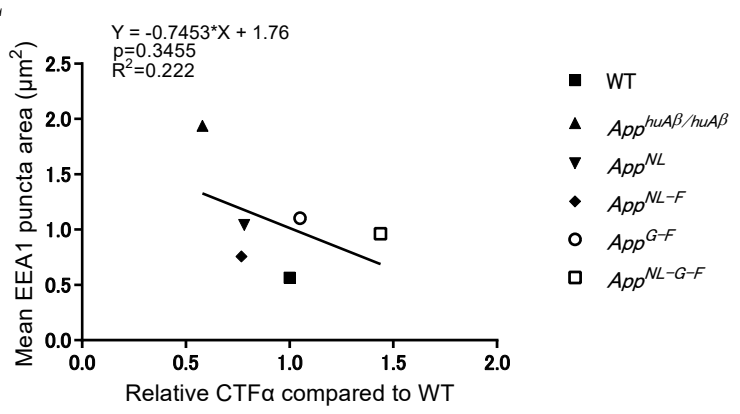

\section{Figure S4. Analysis of APP CTFs and endosomal abnormalities}

(A) CTF- $\alpha$ levels did not correlate with the area $\left(\mu \mathrm{m}^{2}\right)$ of EEA1 $1^{+}$. (B) Number of EEA1 ${ }^{+}$signals per $\mu \mathrm{m}^{2}$ was increased in App-knock-in mice except for $A p p^{h u A \beta}$ mice. (C) Mean EEA1 puncta area. (DE) No correlation was observed between mean EEA1 ${ }^{+}$puncta area and levels of CTF- $\beta$ (D) or CTF$\alpha(E)$. Pearson correlation coefficient $\mathrm{R}$ and $\mathrm{p}$ value are shown along with the linear regression equation (A), (D) and (E). Each bar represents the mean \pm SEM. $* P<0.05, * * P<0.01$, ${ }^{* * *} P<$ 0.001. (WT; n=3,App $p^{h u \beta} ; \mathrm{n}=3, A p p^{N L} ; \mathrm{n}=3, A p p^{N L-F} ; \mathrm{n}=3, A p p^{G-F} ; \mathrm{n}=3$ and $A p p^{N L-G-F} ; \mathrm{n}=3$, one-way ANOVA followed by Turkey's multiple comparison test) (B) and (C). 


\section{Supplemental Table 1}

\begin{tabular}{|c|c|}
\hline \multicolumn{2}{|l|}{ sgRNA } \\
\hline T7_sgRNA_moAPP & TGTAATACGACTCACTATAGGAAGACGGAAGAGATCTCGGA \\
\hline _NL_KM_F & AGTTTTAGTACTCTGGAAACAGAATC \\
\hline \multirow{2}{*}{$\begin{array}{l}\text { sgRNA_SaCas9_tail } \\
\text { _R }\end{array}$} & AAAAATCTCGCCAACAAGTTGACGAGATAAACACGGCATTT \\
\hline & TGCCTTGTTTTAGTAGATTCTGTTTCCAGAGTACTAAAAC \\
\hline \multicolumn{2}{|l|}{ SaCas9 mRNA } \\
\hline T7-SaCas9-F & TAATACGACTCACTATAGGGCCCCATTGACGCAAAT \\
\hline T7-SaCas9-R & GGCAACTAGAAGGCACAGTCGA \\
\hline \multicolumn{2}{|l|}{ ssODN } \\
\hline APP-Ex16- & caatctcggggagaggcagtttattttgcctacCAGTTTTTGATGGTGGACTTC \\
\hline \multirow[t]{3}{*}{ NL_KM_ssDNA } & ATATCCTGAATCATGTCTGAATTCTGCATCCATCTTCACTTC \\
\hline & CGAGATCTCTTCCGTCTTGATGTTTGTCAGCCCAGAAC \\
\hline & ctgcgtcaaacacaaagtatgcagggecatccgttagtgtgaccgccagccacaaggaggcaaa \\
\hline
\end{tabular}

Table S1.Information on primers and oligonucleotides used for the synthesis of sgRNA, SaCas9 mRNA and ssODN.

In vitro synthesis of CRISPR tools was performed with the listed primers for the generation of App $^{G-}$ $F$ and $A p p^{h u A \beta}$ mice. See Methods for details. 


\section{Supplemental Table 2}

\begin{tabular}{|l|l|}
\hline \multicolumn{2}{|l|}{ Genotyping of the App ${ }^{G-F}$ and $A p p^{\text {huA } \beta}$ mice } \\
\hline moAPP-Ex16-hs-F2 & ACAGGCATTACATATTCAGCGT \\
\hline moAPP-Ex16-hs-R2 & ACTATCAACAGAGCCCCACT \\
\hline \multicolumn{2}{|l}{} \\
\hline Off-target analysis & CCATGCATTGTCTTTGAACCT \\
\hline OFF1-F & CGCCTCTGAATTCCTTGAA \\
\hline OFF1-R & CAGGCTGTGGGATAGGTTTT \\
\hline OFF2-F & CGAGGTCAGCTTGGCTTTTA \\
\hline OFF2-R & CTGAAGAAGAGCCAGCCTCA \\
\hline OFF3-F & TCTCAGGGAATCCACCATTC \\
\hline OFF3-R & AGTAACAGCCCAGGCAGAAA \\
\hline OFF4-F & TGCTAAGACACATAAAAACAAGCA \\
\hline OFF4-R & GGACCCGAGTTTGATTCTCA \\
\hline OFF5-F & CCTGTTTCTTCGGCATGTTT \\
\hline OFF5-R & TTCTCCTTTCAGAAGATGTTTGG \\
\hline OFF6-F & TTTCAATGTTCACCCCATCC \\
\hline OFF6-R & ACGGAAGATTCCAGCTCAGA \\
\hline OFF7-F & CCAGCACTCAATGCATGTTC \\
\hline OFF7-R & GAGACGCTTTTGGACTTGCT \\
\hline OFF8-F & TTTGCCAGCTGCAGATAATTT \\
\hline OFF8-R & TCCTAGAGGAGTTTGGGGATT \\
\hline OFF9-F & GGCCAATGCAGGTAGAATGT \\
\hline OFF9-R & GCCTTTTCATATTGCCCTCA \\
\hline OFF10-F & \\
\hline OFF10-R & \\
\hline &
\end{tabular}

Table S2. List of primers used for the genotyping and off-target analyses.

All primer pairs were used for PCR and subsequence sequencing analyses. The sequential number of the OFF primers corresponds to that of the potential off-target sites shown in Figure 1. See Methods for details. 


\section{Supplemental Table 3}

\begin{tabular}{|l|l|l|}
\hline Antibody & Dilution ratio & \# Manufacturer or reference \\
\hline A $\beta 40$ & $1: 100$ & $\# 10047$, IBL \\
\hline A 342 & $1: 100$ & $\# 18582$, IBL \\
\hline A $33 p E$ & $1: 400$ & Saido et al., 1996 \\
\hline N1D & $1: 200$ & Saido et al., 1996 \\
\hline 82E1 & $1: 500$ & $\# 10326$, IBL \\
\hline EEA1 & $1: 100$ & \#3288, Cell Signaling \\
\hline Iba1 & $1: 200$ & $\# 013-27691$, Wako \\
\hline GFAP & $1: 200$ & \#MAB3402, Millipore \\
\hline PSD-95 & $1: 50$ & \#124011, Synaptic Systems \\
\hline synaptophysin & $1: 200$ & \#61012, PROGEN \\
\hline
\end{tabular}

Table S3. List of primary antibodies used for immunohistochemistry.

Primary antibody dilution ratios are shown. See Methods for details. 